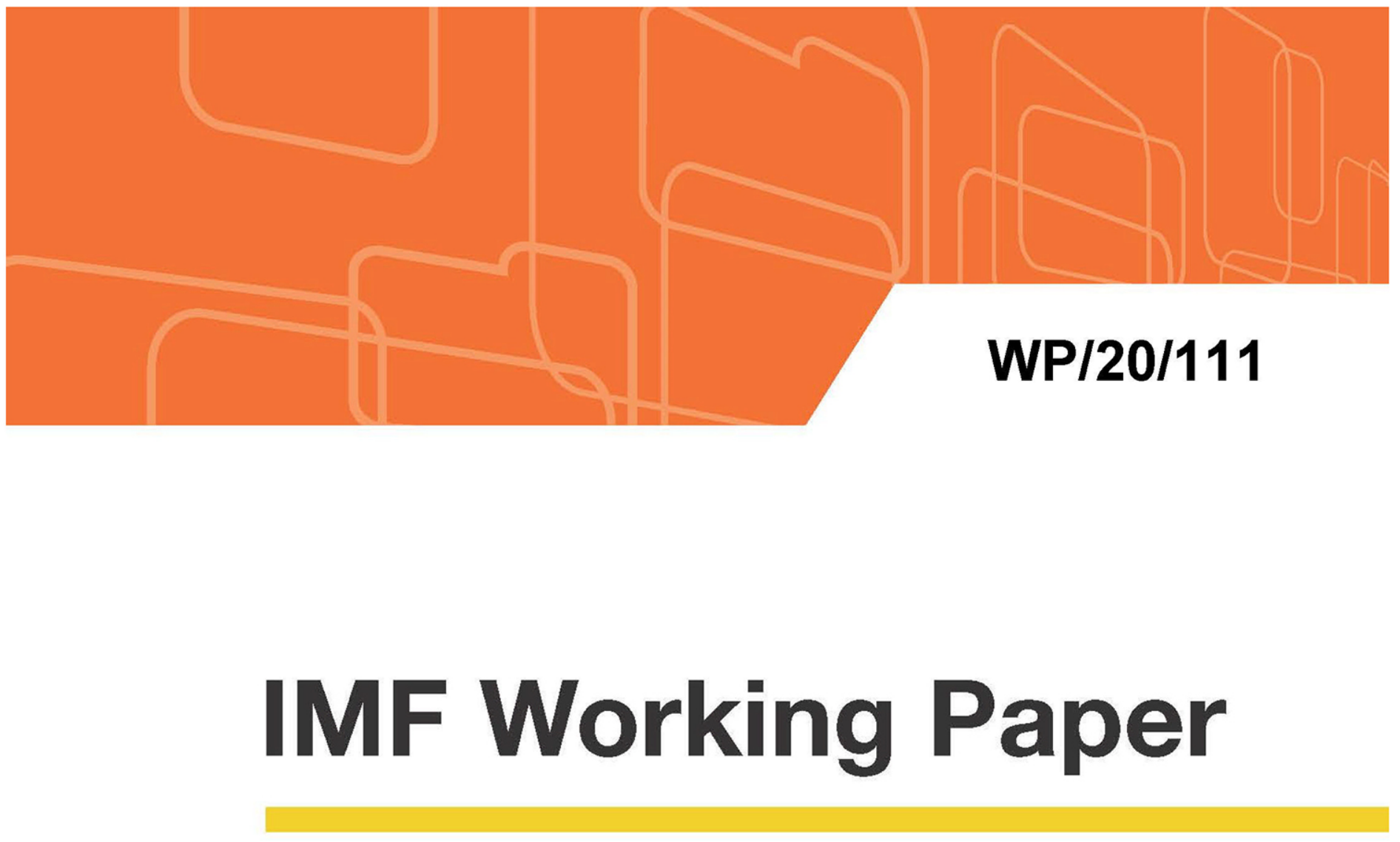

\title{
Expected Credit Loss Modeling from a Top- Down Stress Testing Perspective
}

by Marco Gross, Dimitrios Laliotis, Mindaugas Leika, Pavel Lukyantsau

IMF Working Papers describe research in progress by the author(s) and are published to elicit comments and to encourage debate. The views expressed in IMF Working Papers are those of the author(s) and do not necessarily represent the views of the IMF, its Executive Board, or IMF management. 


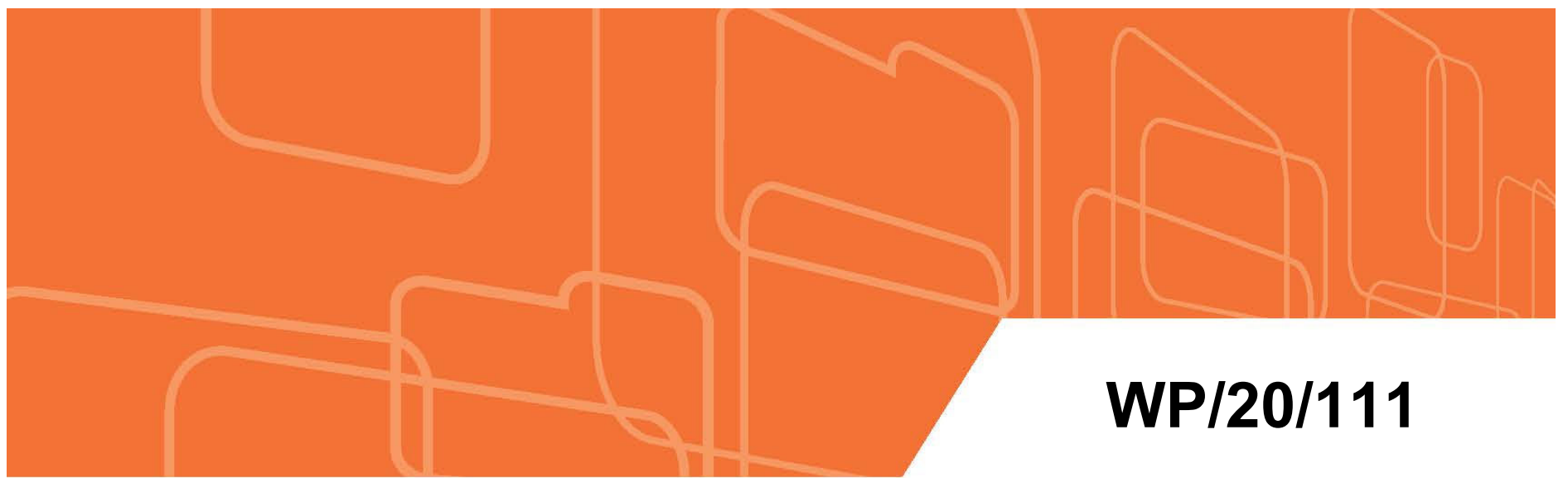

\section{IMF Working Paper}

\section{Expected Credit Loss Modeling from a Top- Down Stress Testing Perspective}

by Marco Gross, Dimitrios Laliotis, Mindaugas Leika, Pavel Lukyantsau

IMF Working Papers describe research in progress by the author(s) and are published to elicit comments and to encourage debate. The views expressed in IMF Working Papers are those of the author(s) and do not necessarily represent the views of the IMF, its Executive Board, or IMF management. 


\title{
IMF Working Paper
}

Monetary and Capital Markets Department

\section{Expected Credit Loss Modeling from a Top-Down Stress Testing Perspective ${ }^{1}$}

Prepared by Marco Gross, Dimitrios Laliotis, Mindaugas Leika, Pavel Lukyantsau

\author{
Authorized for distribution by Martin Čihák
}

July 2020

\begin{abstract}
IMF Working Papers describe research in progress by the author(s) and are published to elicit comments and to encourage debate. The views expressed in IMF Working Papers are those of the author(s) and do not necessarily represent the views of the IMF, its Executive Board, or IMF management.
\end{abstract}

Disclaimer: This document was prepared before COVID-19 became a global pandemic and resulted in unprecedented economic strains. It, therefore, does not reflect the implications of these developments and related policy priorities. We direct you to the IMF Covid-19 page that includes staff recommendations with regard to the COVID-19 global outbreak.

\begin{abstract}
The objective of this paper is to present an integrated tool suite for IFRS 9- and CECLcompatible estimation in top-down solvency stress tests. The tool suite serves as an illustration for institutions wishing to include accounting-based approaches for credit risk modeling in top-down stress tests.

JEL Classification Numbers: M40, G20.

Keywords: Credit risk, IFRS 9, CECL, lifetime probability of default, LGD modeling.

Authors'email addresses: mgross@imf.org, dlaliotis@imf.org,mleika@imf.org, plukyantsau@imf.org

\footnotetext{
${ }^{1}$ The content of this paper has benefited from the experience of applying the analytical ECL tool suite in multiple IMF Financial Sector Assessment Programs (FSAPs). An IMF Macroprudential Stress Testing course led by M. Gross and developed with P. Lukyantsau at the Joint Vienna Institute (JVI), Austria, in April 2019 introduced the framework to an audience of central bank economists and stress test practitioners from Central and Eastern Europe, Caucasus, and Central Asia. Thanks for useful comments and discussions go to the participants of an IMF in-house seminar (November 2019), and specifically to Ibrahim Ergen, Ellen Gaston, Heedon Kang, and Luc Riedweg.
} 


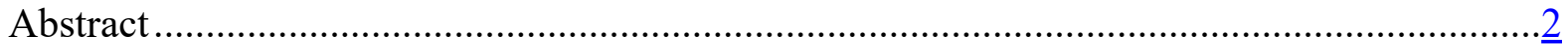

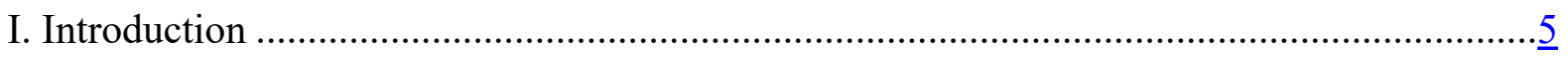

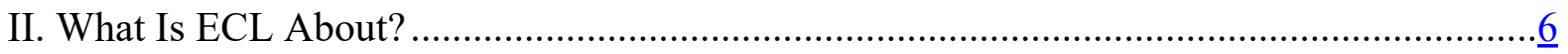

III. An Analytical Tool Suite for Top-Down ECL Modeling ...........................................12

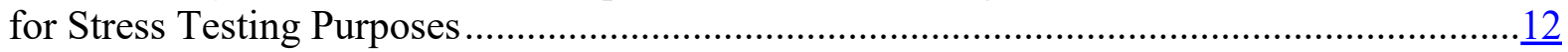

A. Historical One-Factor Representation of Transition Matrices..............................15

B. Linking the One-Factor Representation of Transition Matrices to Macro-Financial

Conditions and Projecting Conditional on Scenarios .......................................... 18

C. Alternative Transition Matrix Model Methods for Weak Data Environments ........ $\underline{21}$

D. An LGD Model for Real Estate-Collateralized Portfolios .................................. 22

E. Lifetime Expected Credit Loss Calculations ..................................................

F. Loan Loss Provision Stock and Flow Calculations .......................................... $\frac{27}{30}$

G. Interplay Between Accounting and Capital Regulation...................................

IV. Perfect Foresight Versus (Few) Multiple Scenarios Versus Monte Carlo Simulations .... $\underline{32}$

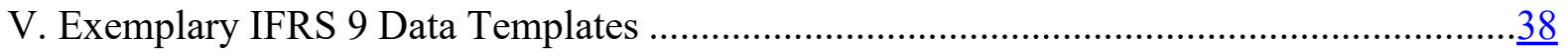

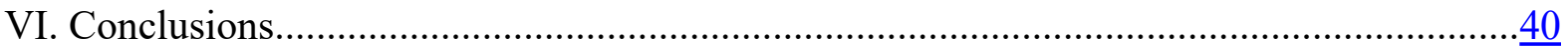

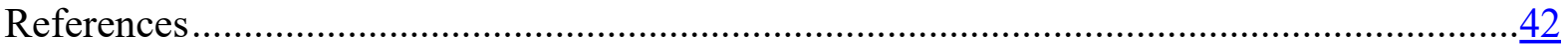

Figures

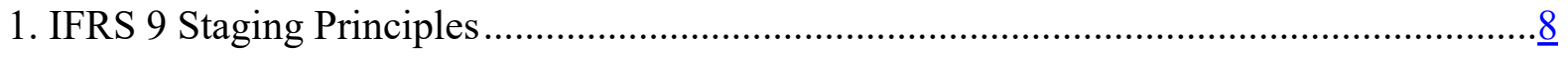

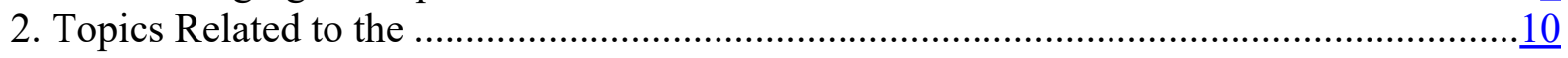

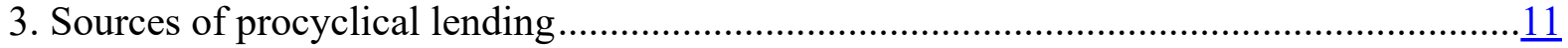

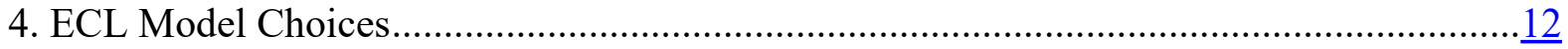

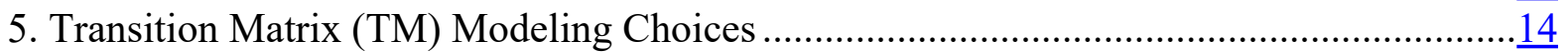

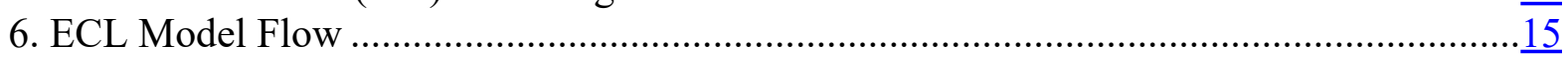

7. IFRS 9 Transition Matrices..................................................................................... $\frac{16}{17}$

8. From Historical Transition Matrices to the Z-score ................................................. 17

9. Uncertainty about Future Sales Price of Collateral Driving LGDs ..................................22

10. Treatment of Risk Parameters beyond an Initial Scenario Horizon under a Perfect

Foresight Stress Test Mode................................................................................... $\frac{34}{39}$

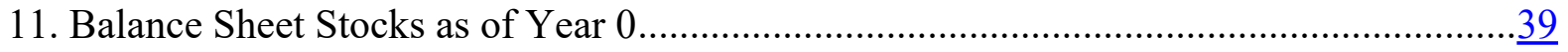

12. Financial Asset Stocks in Stages $1 / 2 / 3$ and Historical Transition Flows ....................... 40

Boxes

1. The Z-Score Methodology ............................................................................... 
2. From Scenario-Conditional Z-Scores to Transition Matrices and Implied S1-2-3 (Performing and Nonperforming) Exposure Stocks ........................................................... 19

3. A Simple and an Advanced LGD Model for Real Estate-Collateralized Portfolios..............23

4. Lifetime Expected Credit Loss (LT-ECL): Formula and Components ...............................26

5. Loan Loss Provision Stock and Flow Calculations ………………………………........... 28

6. Risk Weighted Assets: Linking Regulatory Risk Parameters (IRB) to PiT Risk Parameters

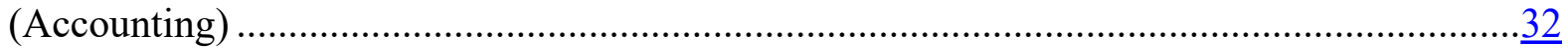

7. Monte Carlo-based Lifetime Expected Loss Distributions Versus Self-Set Scenarios and

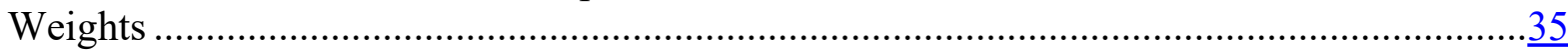




\section{INTRODUCTION}

This paper presents a tool suite for International Financial Reporting Standards 9 (IFRS 9)- and Current Expected Credit Loss (CECL)-compatible top-down stress testing. "Top-down" denotes an institutional perspective, that is, we mean a forward-looking solvency analysis conducted by an oversight organization, such as a central bank, a supervisor, or an international organization such as the IMF while it is conducting stress tests as part of its risk assessment in Financial Sector Assessment Programs (FSAPs). The aim is to present a set of relevant top-down model elements that are instrumental for scenarioconditional expected credit loss (ECL) estimation.

From an accounting perspective, IFRS 9 and CECL — and ECL more generally - aim at moving from a lagged incurred loss to a more time-contemporaneous recognition under the expected loss model. This is useful as it may, for example, prevent banks from providing excessive payouts to shareholders after the onset of material recessions at times when net income may still be positive due to the delayed recognition of losses that are expected to materialize soon. It may help improve investor and market confidence on banks' balance sheet health during economic downturns.

Top-down stress testing has become more challenging amid the complex interplay of regulatory and (new) accounting rules, and generally absent long and granular portfolio-level data in the public domain. All major public stress testing programs (US Federal Reserve, Bank of Japan, European Banking Authority (EBA), European Central Bank (ECB), Bank of England (BoE), and so on) focus on credit losses estimated in line with the relevant accounting regimes. Credit losses are subtracted from banks' capital base, and risk weighted asset (RWA) dynamics are modeled according to regulatory rules. The enhanced complexity is less of an issue for banks, which have granular exposure data at their disposal; it becomes challenging, however, for top-down stress testers without access to granular portfolio data. The paper suggests model methods that top-down supervisors can use in data-weak environments.

The tool suite presented in the paper was designed to limit model complexity and hence data needs. The paper describes multiple modeling options that are based on different levels of data availability. These models and their conceptual underpinnings have been used in various FSAPs since 2018: Canada, France, Korea, Latvia, and Singapore. ${ }^{2}$ They also have been part of technical assistance missions over the past two years.

The structure of the paper is as follows: Section 2 starts by summarizing what ECL is about, from an economics perspective. Section 3 presents a tool suite comprising various analytical components for ECL modeling. The ECL Model Suite accompanies this paper. Section 4 focuses on the concepts of multiple scenarios, perfect foresight, and related aspects.

\footnotetext{
2 The related technical notes documenting the stress test methodologies and results include the following: 2019 France FSAP (IMF 2019a), 2019 Singapore FSAP (IMF 2019b), 2019 Canada FSAP (IMF 2020a), 2019 Korea FSAP (IMF 2020b), 2019 Latvia FSAP (IMF 2020c).
} 
Section 5 presents some exemplary database template structures for the collection of CECL/IFRS 9-relevant data from financial institutions. Section 6 concludes.

\section{What Is ECL About?}

ECL accounting for financial instruments was promoted shortly after the 2007-09 global financial crisis (GFC) as a result of the call to overhaul the accounting principles that existed at that time. One outcome of the G20 meeting in London in April 2009 was the decision to strengthen the post-GFC financial system. ${ }^{3}$ A criticism of the previous accounting regime was that it was too backward-looking and too often deferring the recognition of loan losses. For these and related reasons, it was thought to contribute to procyclical dynamics, that is, the previous accounting regime was seen as partly responsible for the build-up of the imbalances that led to the GFC. ${ }^{4}$

The IFRS 9 accounting principles were published in 2014 and became effective on January 1, 2018.5 As of end-year 2018, 144 of 166 countries (87 percent) that the International Accounting Standards Board (IASB) surveyed require the IFRS standards (however, not all IFRS countries have adopted IFRS 9 specifically). Concerning the G20 subset of countries, five of the 20 do not currently follow IFRS. These include China, India, Indonesia, Japan, and the United States. Although China, India, and Indonesia have not adopted IFRS, their accounting standards are close and converging to IFRS. Japan permits IFRS as one of four sets of accounting standards (in addition to Japanese Generally Accepted Accounting Principles (GAAP), its Modified International Standards (JMIS), and the U.S. GAAP) that listed firms in Japan can use to file their consolidated financial statements. Despite the few exceptions of the G20, overall it is a significant portion of countries that face the new accounting standard. IFRS 9 was transposed into European Union (EU) law by the European Commission in 2016 (EC 2016).

\section{In June 2016, the Financial Accounting Standards Board (FASB) called for the} adoption of the CECL approach (FASB 2016). This standard is adopted in the United States. Other countries, such as Japan and Switzerland, allow their banks - mostly those that are publicly listed in the United States - to use it optionally for reporting purposes. In the United States, the effective implementation date ${ }^{6}$ was December 15, 2019 for public firms that met the definition of a U.S. Securities and Exchange (SEC) filer, excluding entities eligible to be a smaller firm as defined by the SEC. The effective date of CECL for smaller

\footnotetext{
${ }^{3}$ A related Financial Stability Board (FSB) report was published in April 2009. See FSB (2009).

${ }^{4}$ The International Accounting Standards Board (IASB), which develops the IFRS standards, initially worked jointly with the Financial Accounting Standards Board (FASB) in the US, aiming to improve, simplify and harmonize global accounting standards. The two boards split up when they could not agree on certain core principles, in particular related to the expected loan loss provisioning principles.

5 The main reference for the IASB's IFRS 9 accounting framework is IASB 2014.

${ }^{6}$ See FASB News Release 11/15/2019, available at: https://www.fasb.org/jsp/FASB/FASBContent_C/NewsPage\&cid=1176173776362.
} 
firms has been delayed until January 2023. Banks have been given the option to delay the implementation of CECL through the CARES Act. ${ }^{7}$

This paper focuses on ECL accounting as relevant under both the IFRS and CECL regimes, while abstaining from discussions about procyclicality as well as national supervisory approaches to provisioning. Many countries continue to require banks to follow supervisory guidelines for loan loss provisioning as an overlay to accounting provisioning. National accounting standards tend to be applicable for smaller banks and on an unconsolidated basis in many countries, for example, in the EU and various emerging market economies. It is common to operate with dual loan loss provisioning regimes when banks are required to provision according to a loan classification scheme.

IFRS 9 consists of three categories that reflect the changes compared to the previous accounting regime (IASB 2014). They include (1) the classification and measurement of financial assets and liabilities; (2) the expected loss-based impairment model principles; and (3) hedge accounting. In terms of impact on stress testing practices, the most significant category is the second, in which lies the foundation of this paper. ${ }^{8}$

\section{At the heart of the ECL-based impairment model under IFRS 9 lies its risk-based categorization of financial assets (staging) along with stage-specific provisioning.} Figure 1 visualizes these staging principles. Exposures generally enter Stage 1 upon origination. Depending on their change in default risk since origination, they may move to Stage 2 or 3. IFRS 9 is principle-based, implying that here - as in numerous other respectsbanks can decide how to define the criteria for such stage transitions, subject to guidance and a minimum set of transition triggers set by the IASB (IASB 2014). Stage 1 assets are to be provisioned with a 12-month horizon; Stages 2 and 3 assets with a lifetime horizon. For the FASB's CECL approach, no such staging is required as all exposures are subject to the lifetime provisioning principle. The move to ECL was a step to address the "too little, too late" concerns with provisioning under the previous accounting regime. Under IFRS 9, the provisioning can now be characterized as "a bit more, and earlier".

\footnotetext{
${ }^{7}$ https://gbq.com/cares-act-provides-option-to-delay-ceclreporting/\#: :text=The $\% 20$ Coronavirus $\% 20 \mathrm{Aid} \% 2 \mathrm{C} \% 20$ Relief $\% 20$ and,credit $\% 201$ oss $\% 20(\mathrm{CECL}) \% 20$ standard.

${ }^{8}$ Useful references that cover the changes in classification of financial assets and liabilities include EY (2016/18a/b), PWC (2017/18), and Deloitte (2018). In addition to such useful material developed by consultancy firms, the IASB's own IFRS 9 text (2014) is amenable, including numerous illustrations, examples, annexes, and so on. to explain all aspects of IFRS 9.
} 


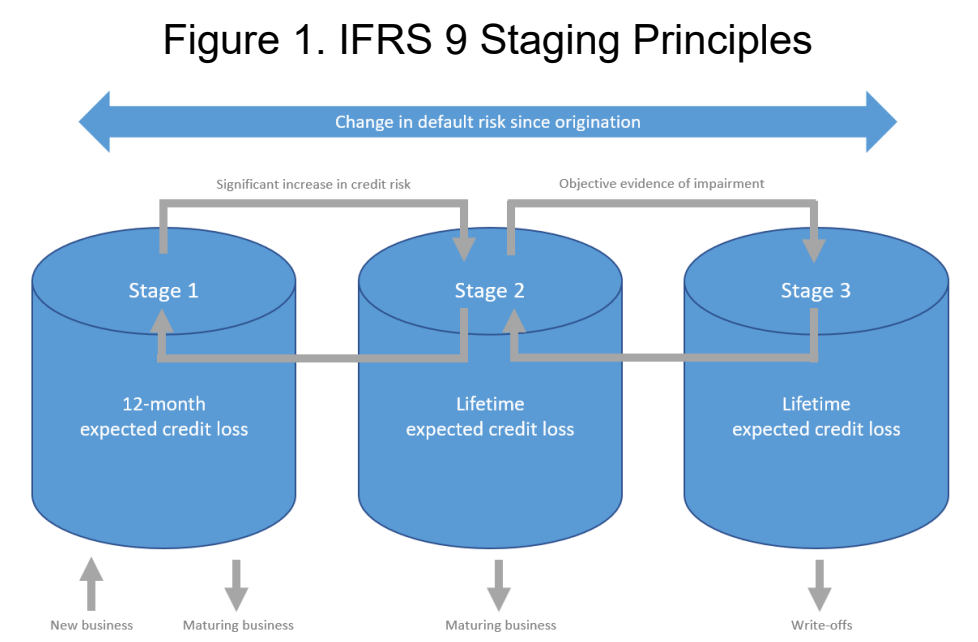

Notes: The schematic visualizes the principles underlying the credit risk staging in line with IFRS 9. The migration between stages is based on a set of criteria that are meant to relate to the change in default risk of financial assets since origination. Under the US CECL approach, Stage 1 exposures are provisioned for with a lifetime horizon as well; hence the distinction between Stage 1 and Stage 2 is obsolete. See text for details.

Figure 2 provides an overview of broader economic implications of ECL accounting. The components shown underlie the question of whether the move from IAS 39 to IFRS 9 and the adoption of the CECL approach in the United States imply more or less procyclical economic dynamics relative to the previous accounting regime, and in comparative terms of the two new frameworks as well.

The implementation of ECL accounting rules in the US, and the third year of the application of IFRS 9 in other jurisdictions, coincided with the outbreak of the COVID19 pandemic and implied concerns over the negative effects of the standard on credit provision to the economy. CECL requires financial institutions to make immediate provisions based on expected credit losses over the lifetime of loans. We presume that any current negative developments in the economy would have higher weight at the origination of a loan, while potential recovery scenarios would have lower weight. This may make the origination of loans expensive, and banks may in some cases decide not to originate new loans altogether, thus further amplifying the already tight financial conditions.

Relief measures and a strong monetary policy response were meant to counteract the upward pressure on loan prices. Strong monetary policy responses (decreasing policy rates where possible) coincided with capital relief measures, which in terms of ECL ranged from a temporary postponement of the requirements to allowing institutions to use transitional arrangements. ${ }^{9}$ Further guidance was issued on the definitions of moratoria, loan forbearance and defaults, and the treatment of sovereign guarantees (EBA 2020). The IASB stressed that

\footnotetext{
${ }^{9}$ See Board of Governors: March 31, 2020 Joint Statement on the Interaction of Regulatory Capital Rule: Revised Transition of the CECL Methodology for Allowances with Section 4014 of the Coronavirus Aid, Relief, and Economic Security Act; Single Supervisory Mechanism: April 1, 2020 IFRS 9 in the context of the coronavirus (COVID-19) pandemic; Prudential Regulation Authority: March 26, 2020. COVID-19: IFRS 9, capital requirements and loan covenants.
} 
IFRS 9 models should not be used mechanistically, and that government support measures shall be considered in determining lifetime losses. ${ }^{10}$ All these measures aimed at preserving banks' capital so they could expand the balance sheets and continue providing credit to the borrowers. In this sense, regulatory measures were countercyclical.

Considering the pandemic, the Single Supervisory Mechanism (SSM) and the ECB recommended that banks may employ centrally defined macroeconomic scenarios. The SSM and ECB suggested that banks employ centrally defined scenarios (ECB forecasts) to address scenario uncertainty and to avoid possibly excessive increases in provision levels in the event that banks would use more conservative scenarios (ECB 2020, SSM 2020).

Principle-based accounting implies that numerous implementation choices are left to the discretion of banks. Under both CECL and IFRS 9, banks have a choice in terms of setting probabilities of adverse scenarios as well as levels of severity of adverse scenarios themselves. Under IFRS 9, financial institutions are setting the criteria for assets to move from Stage 1 to 2. A cross-bank comparison of accounting and hence also regulatory capital metrics ${ }^{11}$ is less easy if different criteria are implemented across banks, which may be disadvantageous for investors and supervisors. Moreover, banks may exploit their leeway in implementing the framework in a way that minimizes impairment charges and thereby maximize net income flows and residual capital.

The ECL regime brings about significant modeling challenges, complexity, and hence model risk. The IFRS 9 and CECL model requirements are complex, thus expertise must be built up over time. Building operational models nowadays means that data need to be sourced and processed retrospectively from history, while in the future the data will accumulate and be of increasingly better quality. It is useful to note that in relation to "model risk," neither the IFRS 9 nor the CECL accounting framework contains any reference to back-testing requirements. ${ }^{12} \mathrm{CECL}$ implies less model risk from a top-down stress test perspective (except for that related to lifetime loss calculations), since there is no distinction between Stage 1 and 2.

The move to the ECL accounting regime connects to a long debate about the pros and cons of fair-value versus book-value accounting. One argument for fair-value accounting in general, and IFRS 9 and CECL specifically, lies in the timelier recognition of losses after an ensuing recession. Banks will thus be restricted to otherwise paying out sizeable dividends at such a time, despite the expectation that losses would be incurred soon after (as observed for several European banks after the onset of the GFC). A discussion of pros and cons of fairvs. book-value accounting is beyond the scope of our paper; useful entry points to the related literature include Laux and Leuz (2010), Allen and Carletti (2008), and Beatty et al. (1996).

\footnotetext{
${ }^{10}$ IFRS, March 27, 2020. IFRS 9 and covid-19 https://cdn.ifrs.org/-/media/feature/supporting-implementation/ifrs-9/ifrs-9ecl-and-coronavirus.pdf?la $=$ en

${ }^{11}$ Due to the interplay between accounting and regulation (a related short discussion follows later in the paper).

12 The BCBS (2015) guidance on ECL accounting lists back-testing as one best practice that banks shall consider when developing their ECL-compatible credit risk methodology (see BCBS 2015, para. 31).
} 


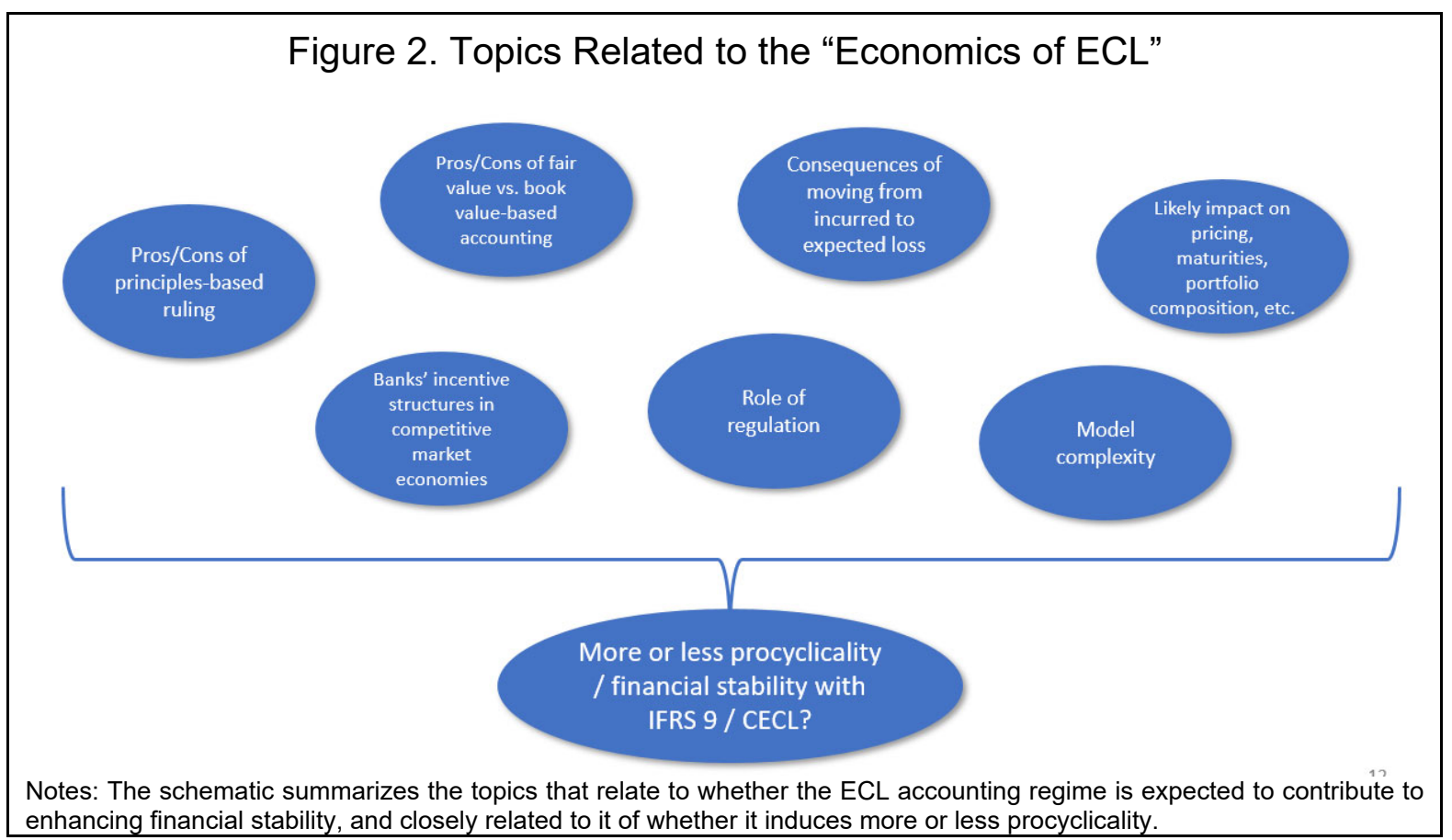

A range of factors contribute to cyclical economic dynamics, one of which is seen in an accounting regime. Procyclicality has been defined, for example, by the Financial Stability Forum (2008), as the "mutually reinforcing ('positive feedback') mechanism through which the financial system can amplify business fluctuations and possibly cause or exacerbate financial instability." Such definition resembles the concept of the financial accelerator as coined in the literature (Bernanke et al. 1999, Kiyotaki and Moore 1997). Figure 3 visualizes a perspective on different factors that may contribute to procyclical lending. The box titled "regulation/policy" refers to the role of regulatory and accounting regimes for implying procyclical lending dynamics.

The procyclical dynamics of IFRS 9 and CECL are highlighted in the literature. Abad and Suarez (2017) have developed a bank portfolio model, calibrated to match the corporate loan portfolio of an average European bank. Their simulation results suggest that the IFRS 9 and CECL adoption implies a more pronounced response of provisions to a negative credit shock than under the incurred loss regime. The authors point to the critical role of regulatory authorities to monitor and intervene when necessary through regulatory remedial actions, such as a release of the counter cyclical buffer (CCyB). Huizinga and Laeven (2019) find that heterogeneity of assumptions used by banks in the euro area led to considerable differences in provisioning and that the introduction of IFRS 9 is unlikely to cure that problem. Chae et al. (2018) analyzed the impact of CECL on US banks and came to similar conclusions, that the comparability of provisions across banks and time will be complicated due to differences in assumptions about the future path of macro-financial variables. ${ }^{13}$

\footnotetext{
${ }^{13}$ Additional references to the growing literature on the financial stability implications of IFRS 9 include Buesa et al. (2019), ESRB (2017), Novotny-Farkas (2015), Bushman and Williams (2015), and Gaston and Song (2014).
} 
Various industry surveys document that banks expect(ed) the move to IFRS 9 to have an impact on loan pricing. Such industry surveys include Deloitte (2018), EBA (2016), and EY (2016). The EBA (2016) suggested that " $60 \%$ of the banks anticipate that IFRS 9 impairment requirements will have an impact on lending practices of banks in terms of the pricing of products." This suggests that in the past, banks were not pricing their loans based on a lifetime expected loss basis, which in principle they would, regardless of any accounting regime (and the provisioning horizon specifically). This proposition assumes that banks price their loans in a way that covers their cost of funding, expected losses, and cost of capital.

Banks' incentive structures, seen against the principle-based accounting framework, play an important role in whether more or less procyclical dynamics can be expected as a result of IFRS 9. Numerous research papers document that banks are intentionally biasing their risk parameters (such as probabilities of default (PDs) and loss given default (LGDs)) used to calculate expected and unexpected losses to an optimistic side. ${ }^{14}$ The concepts of herding and competition are interrelated (Figure 3). They may imply that even if bank managers would foresee a recession, competition may dissuade managers from acting, that is, to intentionally not yet move Stage 1 assets to Stage 2 . That move would imply a charge that would reduce net income and, in the sequel, lower dividend payouts, and imply a loss in market share.

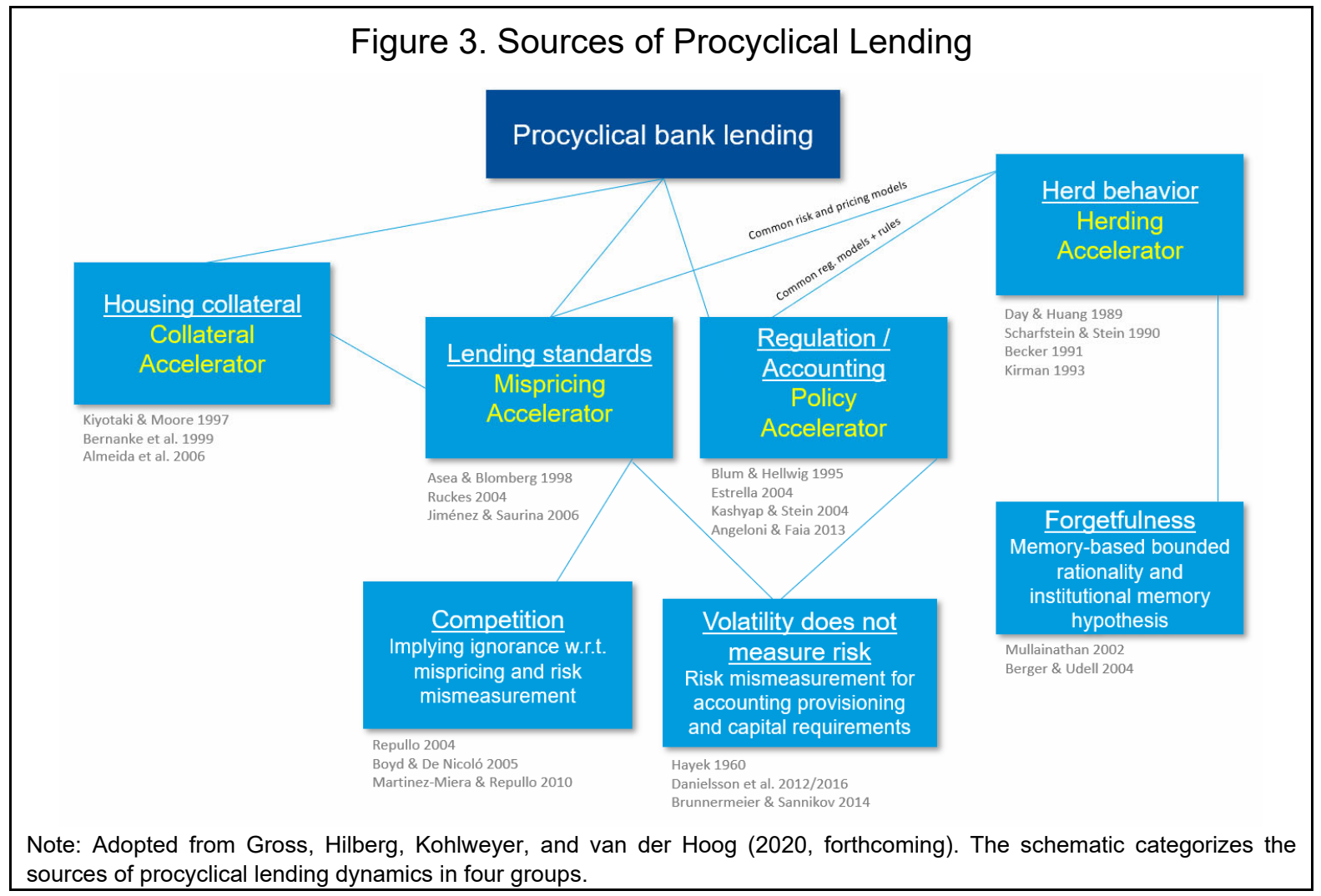

\footnotetext{
${ }^{14}$ Useful entry points to this field in the literature include Behn et al. (2016), Firestone and Rezende (2016), Mariathasan and Merrouche (2014), Haldane (2013), Plosser and Santos (2014), and Begley et al. (2017).
} 
Numerous policies can be considered for counteracting procyclical dynamics, including those arising from the accounting regime. One set of tools includes the reliance on dynamic capital buffers (for example, countercyclical capital buffers) to counterbalance procyclical accounting provisioning, for example, by releasing such buffers to mitigate cliff effects at the onset of recessions. Stress testing is another one. It can be used to inform Basel Pillar 2 capital requirements and Pillar 2 guidance as set by the ECB/SSM, and to set stress test-based buffers as considered by the US FED ("stressed capital buffers") and the BoE. For a stress test assessment to inform such buffers, it needs to follow countercyclical (statedependent) scenario design to thereby counteract procyclicality, including as one source the accounting provision scheme. Finally, a more stringent supervisory regime that allows supervisors and auditors to challenge banks' own tools, assumptions, scenarios, and provisions may be helpful. That requires developing a suite of top-down ECL models. We propose an analytical top-down ECL modeling tool suite in the following chapter.

\section{An Analytical Tool Suite for Top-Down ECL MOdeling FOR STRESS TESTING PURPOSES}

\section{Numerous approaches can be considered for operationalizing ECL modeling for top-} down stress testing. Figure 4 summarizes these approaches in four high-level categories. Aggregate loss models based on historical loan loss provision rates or write-off rates may be considered. These may include regression models that link loss rates to macro-financial conditions, in turn to be able to project losses conditional on scenarios. Second, transition matrix (TM) models can be used, with different options available for capturing their dependence on macro-financial conditions. Third, vintage model approaches can be used, which allow tracking the credit risk characteristics of exposures depending on when they were originated (though they are data-demanding). Fourth, loan level data-based models are the most "micro" in nature, being sourced from bank loan tapes historically, or credit registers (centrally collected loan tapes of banks). These models capture the migration of individual exposures over time.

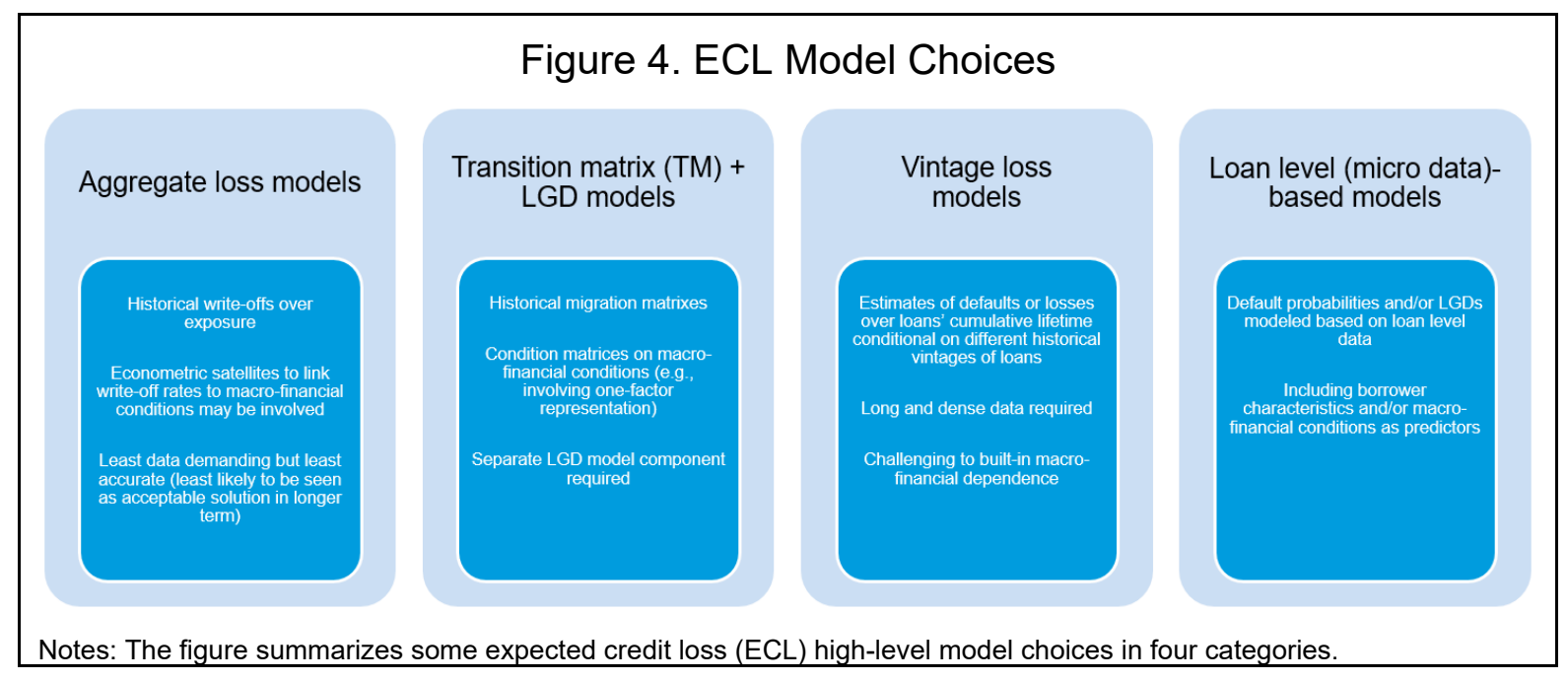




\section{TM models are useful for stress testing financial institutions under the IFRS 9} accounting regime. A TM-based approach for IFRS 9 may strike a useful balance between the richness of the data and model complexity, while being able to operate with portfoliospecific data, distinguishing between PDs and LGD dynamics, and working with a framework that allows conducting a top-down macro-financial, scenario-conditional forecast of loan losses. ${ }^{15}$

\section{While the aggregate loss model approach would be insufficient as a modeling device} under IFRS 9, it can be useful under a CECL regime. ${ }^{16} \mathrm{CECL}$ does not require modeling TMs, but the estimation of lifetime PDs and LGDs. These can be derived from historic loss models by considering multiple scenarios and vintages of loans. For example, DFAST/CCAR stress testing models in the US use accounting data and can be augmented with loan vintage data to derive lifetime ECLs. At the same time, loan level vintage models are data intense and require inputs that may not be available to institutions in charge of topdown macro-prudential stress testing. Such micro-level data may accrue over time and hence imply that micro data-based models can be further developed in the future.

The models presented later focus on IFRS 9 transition matrices, while the estimation of lifetime PDs/LGDs is equally applicable under the CECL regime. Various model choices for the IFRS 9 historical TMs can be applied. The notion of "modeling" the historical TMs denotes the step whereby they are related to macro-financial conditions. This step is required for stress testing purposes. Figure 5 summarizes some generic model choices for the TMs.

Two of the four model choices in Figure 5 can be particularly suitable for top-down scenario conditional solvency analyses. These include, first, the log-odds, fractional probit or logit-based modeling of the transition probabilities in the individual cells of a TM. This approach involves a series of regressions of a TM's individual cells on macro-financial variables. ${ }^{17} \mathrm{~A}$ "one-factor representation" of the transition matrix and the subsequent regression of that one-factor on macro-financial variables is a second option. This methodology has been long in use in the financial industry for rating transition matrix modeling (Belkin et al. 1998). We exemplify this methodology as part of the ECL Model Suite. $^{18}$

\footnotetext{
15 This also reflects the institutional perspective of this paper, where for most designated or regulatory authorities, granular data on individual exposures are not usually available.

16 The so-called open-pool and closed-pool (cohort) approaches for calculating historical loss rates are widely used in the US and have been summarized in ABA 2018. These approaches allow calculating historical loss rates over some relevant time windows which would correspond to an average residual maturity of a loan portfolio and thereby allow computing lifetime loss rates. For operationalizing the closed-pool approach, loan level data are needed to identify the origination years and perform the vintage calculations accordingly. ABA 2018 does not address the link of such longer-window-based loss rates to macro-financial conditions.

${ }^{17}$ It is an approach that, in modified form, was employed in 2018 at the European Central Bank during euro area-wide stress tests, conducted jointly with the EBA and the SSM, for benchmark model purposes and quantitative guidance for the participating banks.

${ }^{18}$ Additional entry points to the literature related to TM modeling include Bangia et al. (2002), Lando and Skodeberg (2002), Jafry and Schuermann (2004), Mahlmann (2006), Truck (2008), Truck and Rachev (2009) and Gavalas and Syriopoulos (2014).
} 


\section{Portfolios that are "singular" in nature (sometimes referred to as "low default" portfolios) may need to be exempted from the transition matrix model approach.} Examples of such portfolios include loans to central governments. Exposures in such portfolio segments would likely all remain in the same stage at any point in time. The transition matrix would be sparse, by having only one 1 in the $3 \times 3 \mathrm{TM}$ at any one point in time. Such a reduced-rank matrix could not be modeled using the TM model methods hinted at in Figure 5, as one or two rows thereof would sum to zero at all times. An alternative can be to take the point-in-time PD and relate it to macro-economic factors, as in the past under an IAS 39 regime. If the sovereign loans and debt securities all rest in Stage 1 at the outset of a scenario horizon, then an assumption can be made of whether they are to rest in Stage 1 or move to Stage 2. The move to Stage 2 could be tied to a multiple of the change in the PD, for example by considering a three-fold increase or more to trigger the migration to Stage 2 . The provisioning would switch to a lifetime horizon; the corresponding methodology is presented in Section IV.

\section{The model flow depicted in Figure 6 forms the basis for the ECL Model Suite in this}

paper. Integral to the framework is the concept of the TM. Choosing from among the three options for TM modeling depends on the availability of historical TM data (how to obtain historical data for the TMs at the current juncture, shortly after the introduction of IFRS 9, in January 2018, is discussed later in the paper). IMF FSAPs have used two of the three options so far. Option 1 was employed for the FSAPs in Canada, France, Latvia, and Singapore. Option 2 was employed for the 2019 FSAP for Korea.

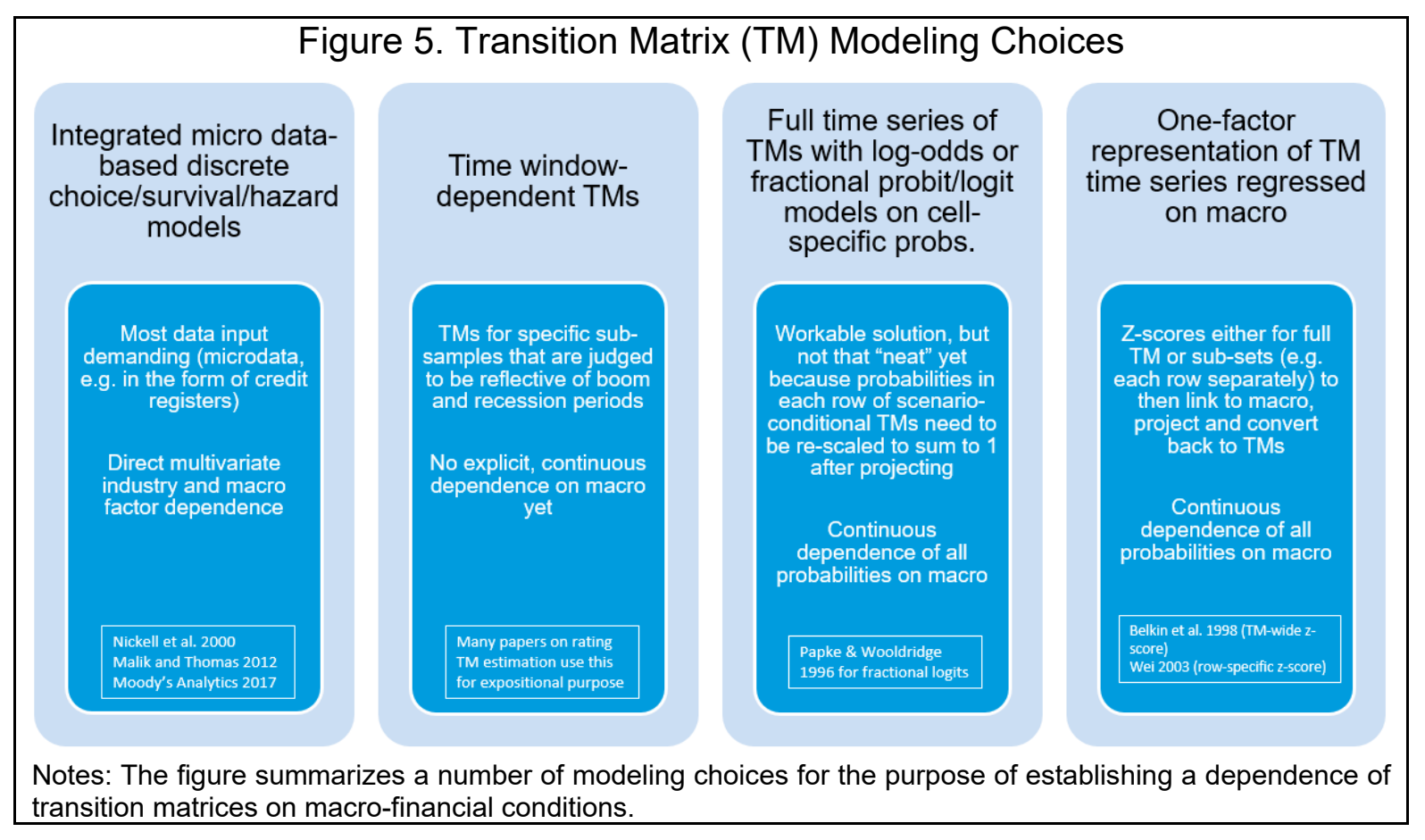




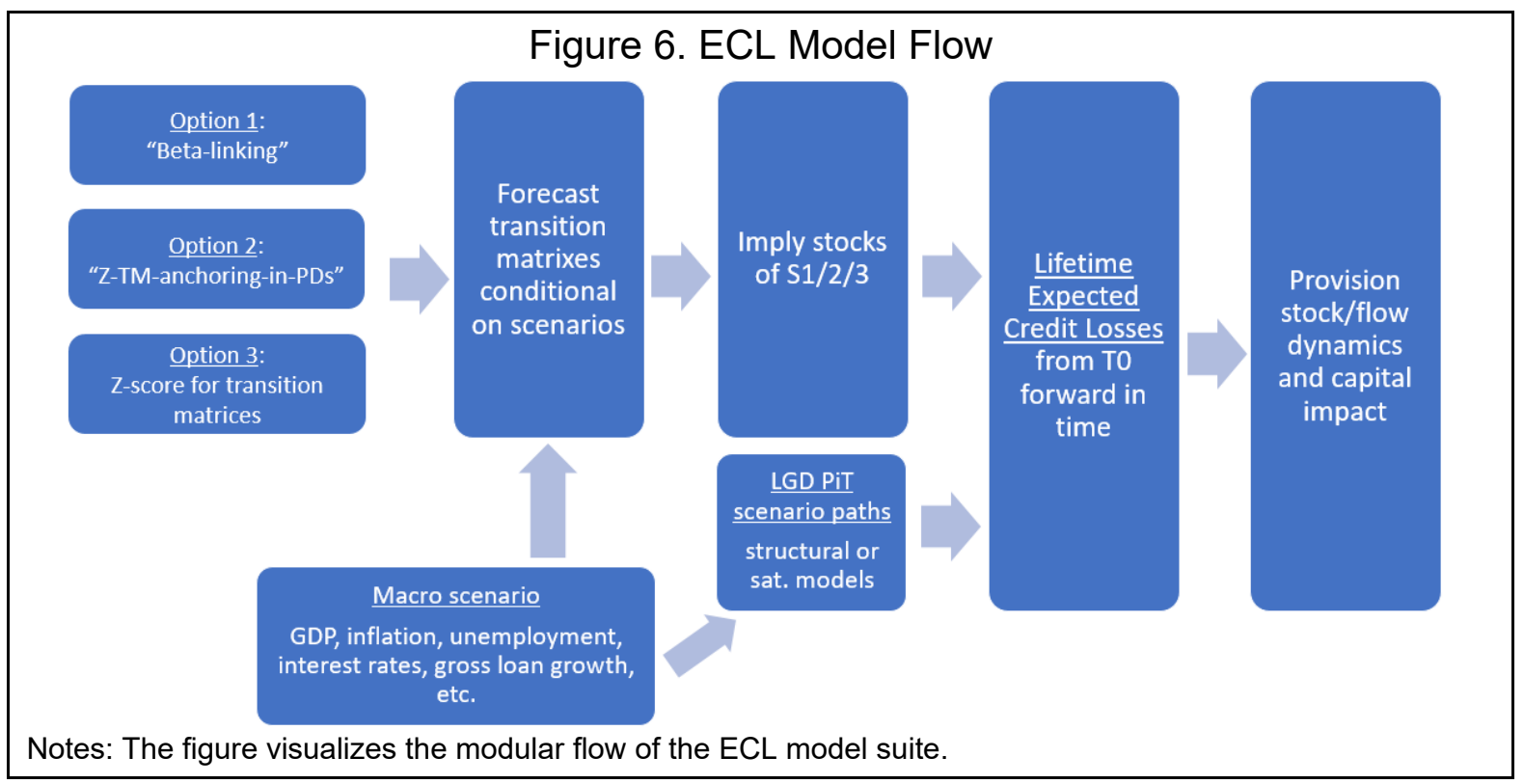

\section{A. Historical One-Factor Representation of Transition Matrices}

Figure 7 depicts two versions of an IFRS 9-oriented transition matrix. They show the flow of assets between the three stages. The two versions of the TM differ in that the second one makes two additional flows explicit: the maturing portion of a portfolio from initial S1 and S2 stocks, and the amounts written off from the beginning of period S3 stocks. In a stress test context, S3 assets can be assumed to be nonperforming, that is, principal is not repaid (and interest is not being paid), and hence the maturing percentage is set to zero (gray in the $\mathrm{TM})$. We can assume that S1 and S2 assets are not written off.

The one-factor representation methodology can work on IFRS 9 transition matrices in the same way as for rating transition matrices. The Belkin et al. (1998) methodology is directly applicable to IFRS 9 TMs, in principle both to the $3 \times 3$ or $3 \times 5$ version of the TM, as illustrated in Figure 7. The maturity and write-off flow percentages can be separately defined, based on assumptions or informed by separate satellite models, linking them to macro-financial variables. The maturing percentage can alternatively be implied by what a new business credit flow and gross loan stock growth from a macro-economic model may require. The write-off percentages depend less on macro-financial conditions, since writeoffs often arise with a notable delay relative to a recession, for example, following increased stringency or forbearance in regulatory requirements. ${ }^{19}$ In some jurisdictions, supervisors may require writing off loans after some period of time (for example, one or two years). In this case, such rules would need to be reflected in the parameterization of write-off rates.

\footnotetext{
${ }^{19}$ Employing simple assumptions, for example, based on historical averages of write-off rates, can therefore be an acceptable option.
} 


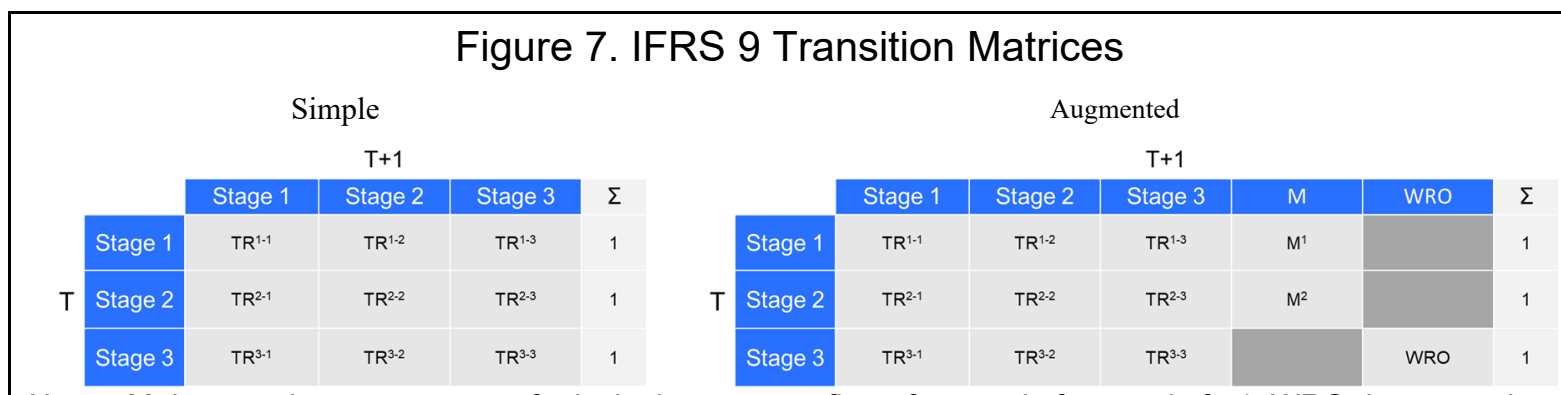

Notes: $\mathrm{M}$ denotes the percentages of principal repayment flows from end of $t$ to end of $t-1$. WRO denotes writeoff flows. Each cell inside the matrices reflects a portion of loans that flow, expressed as a percentage of end of period t stocks as indicated in the first column of the respective row where a percentage is positioned. See text for details.

\section{A "Z-score" can be used to summarize the evolution of a time series of transition} matrices in one number per point in time. Alternative names have been used in the literature and by practitioners, including Z-factor, M-factor, single index, and others. Figure 8 visualizes how the time series of TMs translates into the Z-score. The Z-score is positive during economic expansions, when the transition probabilities referring to the downward move of assets (from S1 to S2 and S3, and from S2 to S3) stand below their longterm averages; likewise, when the probability of "cure" (from S2 back to S1, or S3 back to $\mathrm{S} 2$ or S1) stand above historical averages. The Z-score is negative during recession times, with downgrades from S1 to S2 or defaults into S3 being more sizable than on average historically. Box 1 summarizes how the Z-score methodology works. ${ }^{20}$

\section{The transition matrices would be modeled at the portfolio level, in line with IFRS 9}

guidance. Paragraph B5.5.5 in IASB (2014) suggests that the impairment assessment is to be performed either on individual financial instruments or "collectively on groups of instruments with shared credit risk characteristics". The latter choice is the natural one for stress testers and for the application of a portfolio-based transition matrix methodology. This is because the TM approach cannot work on an individual asset, but a portfolio, by design. A split of the portfolios that is often considered by stress testers in this or similar form includes: nonfinancial corporate loans and securities (optionally split between real estate collateralized and not), financial corporate, mortgage loans, consumer loans and other retail loans, and sovereign loans and securities.

\footnotetext{
${ }^{20}$ The tool suite that accompanies this paper has the Z-score methodology embedded therein.
} 


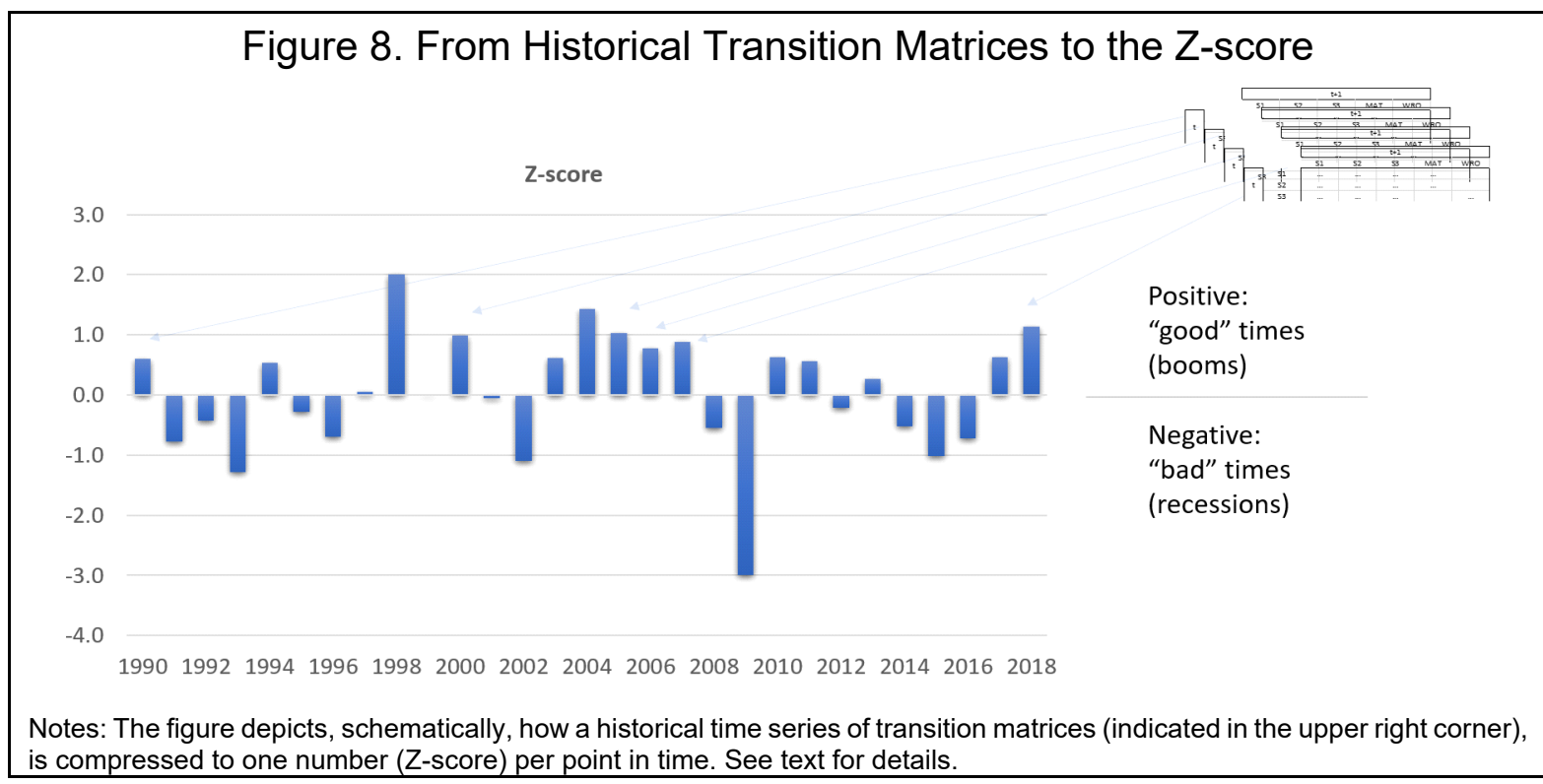

\section{Box 1. The Z-Score Methodology}

The Z-score methodology (Belkin et al., 1998) aims to reduce the information contained in a time series of transition matrices down to one number per point in time. It was originally developed for rating transition matrices, that is, involving letter-based grids of ratings spanning up to 10-15 classes (AAA-D). The methodology is applicable to matrices of any size and irrespective of the criteria set behind the classes in the matrix, and hence equally applicable to a time series of IFRS 9 TMs. Figure 1.1 combines Chart 1 from Belkin et al. (1998) (on the left, for an initial BBB exposure) with a modified version thereof based on an IFRS 9 staging structure (on the right, for an initial S2 exposure in this example). Both refer to a long-term average transition matrix.

Figure 1.1. Probability Density for BBB Rating (left) versus S2 Exposure under IFRS 9

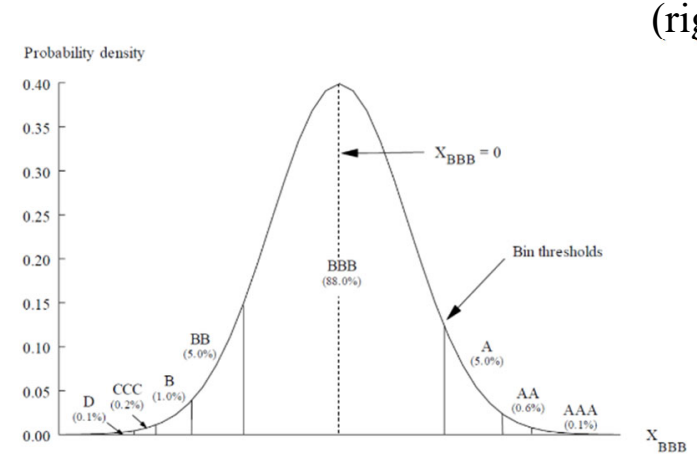
(right)

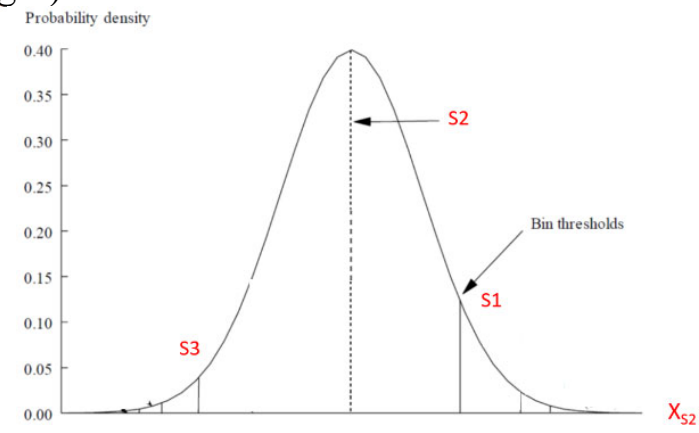

The Z-score method builds on the assumption that the probability density $X$ is a function of an idiosyncratic driver $Y$ and a systematic economy-wide driver $Z$, both of which are independent unit normal random variables by assumption. The parameter $\rho$ captures the correlation between $Z$ and $X$, with $Z$ explaining a fraction $\rho$ of the variance of $X$.

(1) $X_{t}=\sqrt{1-\rho} Y_{t}+\sqrt{\rho} Z_{t}$ 


\section{Box 1. The Z-Score Methodology (concluded)}

The fitted transition probabilities, $\Delta_{t}$, are expressed as follows:

(2) $\Delta_{t}\left(x_{g+1}^{G}, x_{g}^{G}, Z_{t}, \rho\right)=\Phi\left(\frac{x_{g}^{G}-\sqrt{\rho} Z_{t}}{\sqrt{1-\rho}}\right)-\Phi\left(\frac{x_{g}^{G}-\sqrt{\rho} Z_{t}}{\sqrt{1-\rho}}\right)$

$\Phi$ is a standard normal cumulative distribution function. The terms $x_{g}^{G}$ are the "bin boundaries" (referring to the vertical lines in Figure 1.1 above), which are computed based on an inverse of a standard normal cumulative distribution function, with reference to a longterm average transition matrix. The historical deviation between an observed and fitted transition matrix can be computed:

(3) $\min _{\mathrm{Z}_{\mathrm{t}}} \sum_{\mathrm{G}} \sum_{\mathrm{g}} \mathrm{W}_{\mathrm{tg}}(\underbrace{\mathrm{P}_{\mathrm{t}}(\mathrm{G}, \mathrm{g})}_{\text {obs. transition rates }}-\underbrace{\Delta\left(\mathrm{x}_{\mathrm{g}+1}^{\mathrm{G}}, \mathrm{x}_{\mathrm{g}}^{\mathrm{G}}, \mathrm{Z}_{\mathrm{t}}, \rho\right)}_{\text {fitted transition rates }})^{2}$

where the two sums in this equation indicate a summation over all elements in a transition matrix ( $3 \times 3=9$ in an IFRS 9 transition matrix). Conditional on a $\rho$ and the bin boundaries from the long-term average transition matrix, a $Z_{t}$ can be found for each point in time that minimizes the above expression. Since $\rho$ is unknown as well, a "double-loop" can be considered, as suggested in Belkin et al. (1998), entailing a search for both the constant $\rho$ and the time series $Z_{t}$ subject to the constraint that the variance of the resulting $Z_{t}$ be equal one. The interpretation of the $Z$-score is that a $+1 /-1$ value for $Z$ denotes a " 1 -standard deviation from normal (long-run average)" conditions. The tool suite that accompanies this paper includes an Excel/VBA-based implementation of the Z-score methodology as outlined here for a time series of IFRS 9 transition matrices. ${ }^{/ 1}$

1/ The Z-score methodology has been implemented in a rather "crude" manner, using an explicit grid search (loop structure) in Excel coupled with a simple VBA routine that conducts a goal seek. It could of course be implemented in a more efficient manner in Matlab, R or other software packages, involving existing numerical optimization routines. The explicit loop structure in the Excel package is just meant to make the functioning of the methodology more explicit.

\section{B. Linking the One-Factor Representation of Transition Matrices to Macro-Financial Conditions and Projecting Conditional on Scenarios}

The next step is to link the historical evolution of a Z-score to macro-financial variables, in turn to be able to forecast the $Z$-score conditional on macro-financial scenarios. This step can be accomplished using standard regression model methods, or as well some methodologies that account explicitly for model uncertainty, such as the Bayesian Model Averaging (BMA) method (Gross and Población 2017). The result would be an econometric bridge equation that relates the $\mathrm{Z}$-score to time contemporaneous and lagged macro-financial variables.

Scenario conditional paths of the Z-score need to be translated back to the evolution of the TM. This step is required because the actual object of interest is the TM, for conducting the subsequent calculations in terms of resulting stock exposures, expected losses, and the provision stocks and flows. Box 2 summarizes the steps and formulas required for translating 
the Z-factor forecast back to a TM path, as well as for subsequently implying the exposure stocks in S1, S2, and S3.

The Z-score-based scenario-conditional forecasting of TMs therefore has two purposes. First, it is the step required for implying the stocks of exposures in S1, S2, and S3. Second, it implies the two default probabilities that are part of the TM, that is, the transition probabilities for the moves from S1 to S3 and S2 to S3. These elements will all be needed for the provision stocks and flow calculations later.

\section{Box 2. From Scenario-Conditional Z-Scores to Transition Matrices and Implied S1-2-3 (Performing and Nonperforming) Exposure Stocks}

Figure 2.1 depicts visually how the previous step (Box 1, and first row in Figure 2.1) compares to the translation of a Z-score path back to a transition matrix (this box, second row in Figure 2.1).

Figure 2.1. From Transition Matrices to the Z-Score and Vice Versa
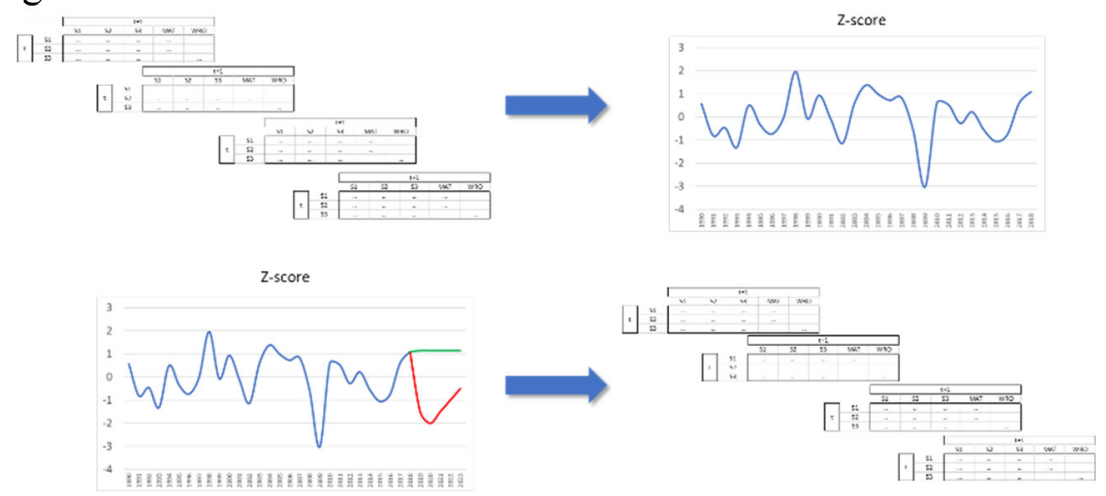

To accomplish what is indicated in the second row of this figure, a transition matrix forecast can be obtained from a conditional Z-score forecast in the same way as historical fit is produced at the estimation stage (Box 1). The formula required to that end has the same structure as equation (2) in Box 1 (equation 6 from Belkin et al. 1998):

(4) $\Delta_{t}\left(x_{g+1}^{G}, x_{g}^{G}, Z_{t}, \rho\right)=\Phi\left(\frac{x_{g+1}^{G}-\sqrt{\rho} \widehat{Z_{t}}}{\sqrt{1-\rho}}\right)-\Phi\left(\frac{x_{g}^{G}-\sqrt{\rho} \widehat{Z_{t}}}{\sqrt{1-\rho}}\right)$

The parameter $\rho$ and the bin boundaries are given at this stage (previously estimated, Box 1) and do not change. Only $Z$ is an input that varies conditional on different scenarios, now denoted as $\widehat{Z}_{t}$, implying the transition probabilities across the transition matrix and along the scenario horizon.

Once the TM paths are obtained, the $3 \times 3$ matrix should be augmented by the scenarioconditional maturing percentages for S1 and S2 exposures as well as the write-off rate assumptions for S3. After adding these percentages in a fourth and fifth column to the matrix (Figure 7, right), each row should be normalized to sum to one again. A formula that can be considered for doing so is:

5) $\mathrm{TR}_{i j}^{*}=\frac{\mathrm{TR}_{i j}}{\sum_{j=1}^{3} \mathrm{TR}_{i j}} \times\left(1-\mathrm{M}_{\mathrm{i}}-\mathrm{WRO}_{i}\right), \forall i=1,2,3$, where only write-offs for initial $\mathrm{S} 3$ stocks would be positive. 


\section{Box 2. From Scenario-Conditional Z-Scores to Transition Matrices and Implied S1-2-3 (Performing and Nonperforming) Exposure Stocks (continued)}

This normalization implies that the pre-defined percentages for the maturing portion and writeoffs will not change due to the normalization in each row of the TM. An alternative that can be considered is to normalize all elements in a row of the TM, including the maturing (M) and write-off (WRO) percentages (the write-off term can be used to capture asset sales as well, e.g., to NPL/asset management firms). The final step now concerns the derivation of the implied S1, S2, and S3 stocks. The formulas that may be used to that end are the following:

$$
\begin{aligned}
& \mathrm{S} 1_{\mathrm{t}}=\mathrm{S} 1_{\mathrm{t}-1}+\underbrace{\mathrm{TR}_{\mathrm{t}}^{21} \mathrm{~S} 2_{\mathrm{t}-1}+\mathrm{TR}_{\mathrm{t}}^{31} \mathrm{~S} 3_{\mathrm{t}-1}}_{\text {Inflows to } \mathrm{S} 1}-\underbrace{\mathrm{TR}_{\mathrm{t}}^{12} \mathrm{~S} 1_{\mathrm{t}-1}-\mathrm{TR}_{\mathrm{t}}^{13} \mathrm{~S} 1_{\mathrm{t}-1}-\mathrm{M}_{\mathrm{t}-1}^{1} \mathrm{~S} 1_{\mathrm{t}}}_{\text {Outflows away from } \mathrm{S} 1} \\
& \mathrm{~S} 2_{\mathrm{t}}=\mathrm{S} 2_{\mathrm{t}-1}+\underbrace{\mathrm{TR}_{\mathrm{t}}^{12} \mathrm{~S} 1_{\mathrm{t}-1}+\mathrm{TR}_{\mathrm{t}}^{32} \mathrm{~S} 3_{\mathrm{t}-1}}_{\text {Inflows to } \mathrm{S} 2}-\underbrace{\mathrm{TR}_{\mathrm{t}}^{21} \mathrm{~S} 2_{\mathrm{t}-1}-\mathrm{TR}_{\mathrm{t}}^{23} \mathrm{~S} 2_{\mathrm{t}-1}-\mathrm{M}_{\mathrm{t}}^{2} \mathrm{~S} 2_{\mathrm{t}-1}}_{\text {Outflows away from } \mathrm{S} 2} \\
& \mathrm{~S} 3_{\mathrm{t}}=\mathrm{S} 3_{\mathrm{t}-1}+\underbrace{\mathrm{TR}_{\mathrm{t}}^{13} \mathrm{~S} 1_{\mathrm{t}-1}+\mathrm{TR}_{\mathrm{t}}^{23} \mathrm{~S} 2_{\mathrm{t}-1}}_{\text {Inflows to } \mathrm{S} 3}-\underbrace{\mathrm{TR}_{\mathrm{t}}^{31} \mathrm{~S} 3_{\mathrm{t}-1}-\mathrm{TR}_{\mathrm{t}}^{32} \mathrm{~S} 3_{\mathrm{t}-1}-\mathrm{WRO}_{\mathrm{t}} \mathrm{S} 3_{\mathrm{t}-1}}_{\text {Outflows away from } \mathrm{S} 3}
\end{aligned}
$$

When steering the stocks of S1, S2, and S3 in this manner forward in time, there would be no explicit control yet over new business flows (they would be zero for now, not added to the S1 equation), and hence the total gross loan stock $(\mathrm{S} 1+\mathrm{S} 2+\mathrm{S} 3)$ would fall if the write-off percentages were positive (gross loan growth would be implied, and negative in this case). To have gross loan growth of a portfolio under explicit control, we consider the following alternative set of equations:

$$
\begin{aligned}
& \mathrm{S} 2_{\mathrm{t}}=\mathrm{S} 2_{\mathrm{t}-1}+\underbrace{\mathrm{TR}_{\mathrm{t}}^{12} \mathrm{~S} 1_{\mathrm{t}-1}+\mathrm{TR}_{\mathrm{t}-1}^{32} \mathrm{~S} 3_{\mathrm{t}-1}}_{\text {Inflows to } \mathrm{S} 2}-\underbrace{\mathrm{TR}_{\mathrm{t}}^{21} \mathrm{~S} 2_{\mathrm{t}-1}-\mathrm{TR}_{\mathrm{t}}^{23} \mathrm{~S} 2_{\mathrm{t}-1}-\mathrm{M}_{\mathrm{t}-1}^{2}}_{\text {Outflows away from } \mathrm{S} 2} \\
& \mathrm{~S}_{\mathrm{t}}=\mathrm{S} 3_{\mathrm{t}-1}+\underbrace{\mathrm{TR}_{\mathrm{t}}^{13} \mathrm{~S}_{\mathrm{t}-1}+\mathrm{TR}_{\mathrm{t}}^{23} \mathrm{~S} 2_{\mathrm{t}-1}}_{\text {Inflows to } \mathrm{S} 3}-\underbrace{\mathrm{TR}_{\mathrm{t}}^{31} \mathrm{~S}_{\mathrm{t}-1}-\mathrm{TR}_{\mathrm{t}}^{32} \mathrm{~S}_{\mathrm{t}-1}-\mathrm{WRO}_{\mathrm{t}-1}}_{\text {Outflows away from } \mathrm{S} 3} \\
& \mathrm{~S}_{\mathrm{t}}=\mathrm{S} 1_{\mathrm{t}}+\mathrm{S} 2_{\mathrm{t}}+\mathrm{S} 3_{\mathrm{t}}=\left(1+\mathrm{g}_{\mathrm{t}}\right) \mathrm{S}_{\mathrm{t}-1} \\
& \mathrm{~S} 1_{\mathrm{t}}=\max \left(0, \mathrm{~S}_{\mathrm{t}}-\mathrm{S} 2_{\mathrm{t}}-\mathrm{S} 3_{\mathrm{t}}\right)
\end{aligned}
$$

The first two equations are the same as under equation (6), the third one implies the gross loan stock based on a period-on-period gross loan growth $g_{t}$, and the last implies the S1 stock as a residual of the gross stock $S_{t}$ and the stocks of $S 2$ and $S 3$. This way, the assumption is that new business enters S1 upon origination, and the maturing percentage for S1 stocks would not actually be needed. The presence of the max operator in the S1 equation is to account for the fact that it may happen that the desired gross loan growth as defined by a macro-financial scenario may not be "achievable," which may happen if gross loan growth was very negative. This would be an extreme case, which should not happen for reasonable parameter inputs, however.

The stock-flow dynamics as outlined in eqs. (6) and (7) involve the S1-2-3 stocks that are specific to IFRS 9. When merging S1 and S2 into performing loans (PL), and calling S3 the nonperforming loan stock (NPL), the familiar stock-flow dynamics as relevant under IAS 39 and CECL emerge: 


\section{Box 2. From Scenario-Conditional Z-Scores to Transition Matrices and Implied S1-2-3 (Performing and Nonperforming) Exposure Stocks (concluded)}

$$
\begin{aligned}
& \mathrm{PL}_{\mathrm{t}}=\mathrm{PL}_{\mathrm{t}-1}\left(1-\mathrm{M}_{\mathrm{t}}-\mathrm{DR}_{\mathrm{t}}\right)+\mathrm{NB}_{\mathrm{t}}+\mathrm{Cure}_{\mathrm{t}} \\
& \mathrm{NPL}_{\mathrm{t}}=\mathrm{NPL}_{\mathrm{t}-1}\left(1-\mathrm{WRO}_{\mathrm{t}}\right)+\mathrm{DR}_{\mathrm{t}}\left(\mathrm{L}_{\mathrm{t}-1}-\mathrm{NPL}_{\mathrm{t}-1}\right)-\mathrm{Cure}_{\mathrm{t}}
\end{aligned}
$$

where $\mathrm{M}_{\mathrm{t}}$ is the maturing percentage of the performing loan stock, $\mathrm{DR}_{\mathrm{t}}$ the default rate, $\mathrm{NB}_{\mathrm{t}}$ the new business flow, and Cure $t_{t}$ the absolute flow of nonperforming back to performing loan stocks. As a side-remark, equation (8) can be solved for the default rate $\mathrm{DR}_{\mathrm{t}}$ and be used to imply historical default rates based on portfolio-level data for performing and nonperforming loan stocks, NPL write-off rates (reflective of asset sales where relevant as well), and cure flows:

$$
\mathrm{DR}_{\mathrm{t}}=\frac{\mathrm{NPL}_{\mathrm{t}}-\mathrm{NPL}_{\mathrm{t}-1}\left(1-\mathrm{WRO}_{\mathrm{t}}\right)+\mathrm{CURE}_{\mathrm{t}}}{\mathrm{PL}_{\mathrm{t}-1}}
$$

\section{Alternative Transition Matrix Model Methods for Weak Data Environments} Several alternatives can be considered when historical transition matrix time series data are short or absent. This is likely the case in the years following the introduction of IFRS 9, in 2018. Figure 6 has indicated three options, including the full Z-score-based methodology, as outlined in subsections A and B (option 3 in Figure 6).

The option referred to as "beta-linking" (option 1 in Figure 6) is useful when the historical time series data for TMs are absent. This option assumes again the availability of historical default rate time series based on which a satellite model would first be developed. The transition rate for S2-3 can be linked to the resulting scenario-conditional PD path, and the transition rate for S1-3 can then be implied so that the weighted average PD matches the PD path from the satellite model. Subsequently, a number of "betas" (hence the name of the method) are involved to link the trajectories of the TR1-3 and TR2-3 to the remaining probabilities in the matrix. These betas could either be based on some (albeit perhaps too short) historical time series data for the transition matrices or be set judgmentally. Moreover, they could be estimated on some jurisdictions' data for which sufficient historical TM data exist, and then be employed for other jurisdictions for which such data are not available. Obviously, the beta-linking method is a suboptimal solution. Robustness analyses should be conducted in terms of the final provision flow, and hence capital impact estimates, to variations in the beta parameters.

The option of "anchoring-in-PDs" (option 2 in Figure 6) is useful when historical time series data for TMs are available but do not cover a full business cycle. In this case, the "pure Z-score" methodology may not be an option because of a concern that the historical sample would not allow capturing the relationship between $\mathrm{Z}$ and macroeconomic factors adequately. The anchoring-in-PDs variant would rely on historical data for default rates, for which data for at least one or more cycles is assumed to be available. A satellite model can in this case be developed for these default rates. Parallel to that, a Z-factor would be computed on the shorter sample for a given bank-loan portfolio. Then, a scenario path for $\mathrm{Z}$ would be set such that the implied PDs (exposure-weighted average of transition rates from S1-3 and 
S2-3) would match the scenario conditional PD path implied by the satellite model, involving the Z-to-TM translation mechanism as outlined in sub-section B and Box 2. The ECL Model Suite which accompanies this paper illustrates the method.

\section{An LGD Model for Real Estate-Collateralized Portfolios}

The LGD component of ECLs is relevant under any accounting regime (including in the former regime under IAS 39). Accomplishing a macro-financial scenario dependence for LGDs implies the need for either an econometric time series model or a structural model for that purpose. Since time series for LGDs are usually not easy to obtain, a structural model choice is considered as part of the analytical tool suite presented here. Two models are presented, one simplistic, the other more advanced. Both models are tailored to real estatecollateralized portfolios (commercial real estate, residential real estate).

The principle underlying both structural model variants relates to the link between the value of real estate collateral and the scenario trajectories for house prices. Real estaterelated firm loan portfolios would link to a commercial property price scenario; mortgage loan portfolios would link to residential property prices. Box 3 summarizes the structure and rationale behind the two LGD model variants. Figure 9 depicts the philosophy underlying the more advanced LGD model, which considers that a loan-to-value ratio (LTV) measured as of a current point in time is deterministic in nature, while the LGD is meant to be forwardlooking and hence subject to uncertainty.

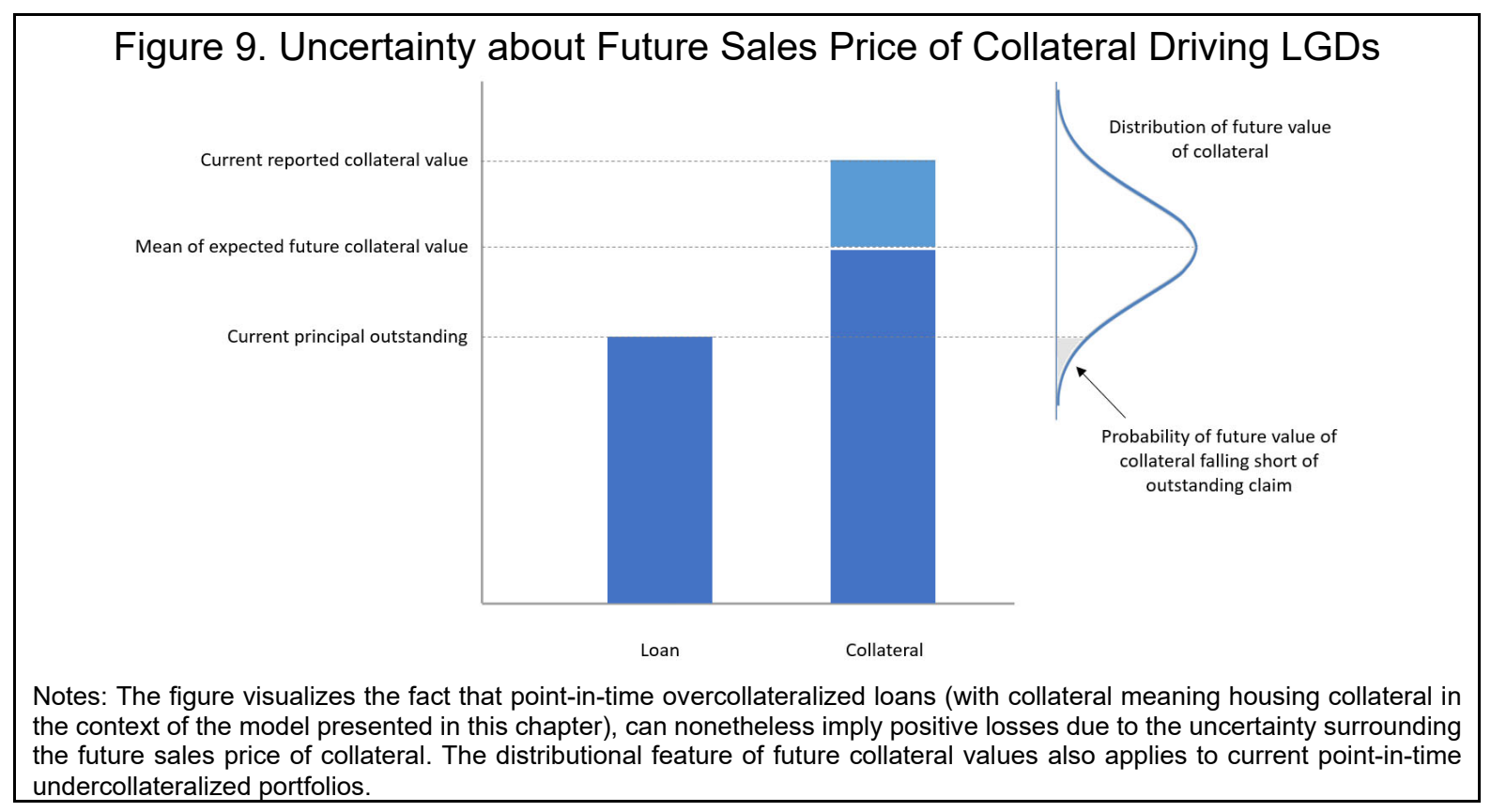

In terms of required data inputs from banks, the two LGD models are not demanding. The simpler model variant requires a set of starting point LGDs for all portfolios that are considered. The advanced model variant requires (1) current portfolio-level LTVs, ideally exposure-weighted; (2) cure rates, available from a T0 transition matrix in an IFRS 9 context (S3-S2/1); and (3) the LGD as of Year 0, all for the relevant portfolios. The LGD module as 
part of the tool suite, coupled with the information provided in Box 3, exemplifies the use of these bank-portfolio-level data.

For uncollateralized portfolios, three model strategies are conceivable. A first option is to refer to historical LGD time series data, when available, and develop econometric satellite models. Second, regulatory downturn LGD estimates can be used to inform an adverse level for an LGD for its accounting provision use in a scenario. Third, aggregate loss rate projections can be decomposed into PDs and LGDs using methods as outlined in Frye and Jacobs (2012) and Frye (2013). It is a method that is also involved in the FED's DFAST methodology (FED 2017).

\section{Box 3. A Simple and an Advanced LGD Model for Real Estate-Collateralized Portfolios}

A simple model that links an LGD to a house price trajectory in a scenario can be designed as follows:

(1) $\operatorname{LGD}(\mathrm{t})=1-(1-\mathrm{LGD}(0)) \times \frac{\mathrm{HP}(\mathrm{t})}{\mathrm{HP}(0)}$

If, for example, an LGD equals 25 percent as of a reference date, and assuming a house price drop of 20 percent, the LGD would rise to 40 percent according to this simple model, as illustrated in the following figure.

Figure 3.1. Numerical Example, Simple LGD Model

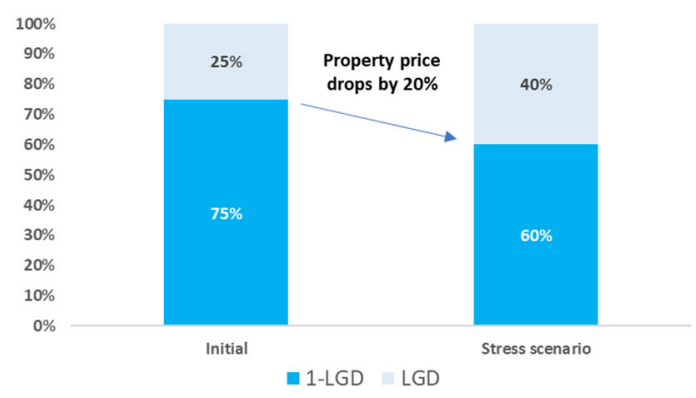

Some caveats apply to the simple model structure: there is no explicit consideration of cures, no account for overcollateralization, and it is effectively treating the LGD as if it was not forward-looking.

The more advanced LGD model starts from the following definition of the LGD (defined as a percentage):

(2) LGD $=((1-$ Probability of cure $) \times$ LGL $)+$ Costs

Costs denotes a percentage that reflects administrative and legal expenses related to the workout of the loan and the collateral sales process. The term "LGL" abbreviates "loss given loss," which is defined as:

(3) $\mathrm{LGL}=\max \left(\frac{\text { Loan-Expected Recovery Value }}{\text { Loan }}, 0\right)=\max \left(\frac{\text { LTV-SR }}{\text { LTV }}, 0\right)$ 


\section{Box 3. A Simple and an Advanced LGD Model for Real Estate-Collateralized Portfolios (continued)}

Having a max operator in this equation is to reflect that banks may not be allowed to keep the proceeds of a collateral sale if the sales price exceeds the outstanding claim, that is, the difference is to be paid back to the earlier defaulted borrower. The expression at the right end of equation (3) was obtained by dividing the numerator and the denominator of the ratio on the left by the reported current collateral value, thereby implying the sales ratio (SR) on the equation's right side. The sales ratio is defined as:

(4) $\mathrm{SR}=\frac{\text { Expected Recovery Value }}{\text { Reported Current Collateral Value }}$

The reported collateral value may deviate from current actual or later realized collateral values for a number of reasons, including, inter alia, (1) that the reported valuation is possibly out of date; (2) that repossessed property tends to be less maintained and hence of lower quality than property that is securing yet performing loans; and (3) fire sale effects, which may arise when banks have to sell in adverse market conditions, that would go beyond the mean of a house price trajectory in a scenario. For these reasons, it is instrumental to assume that the sales ratio has a distribution, for instance, the following modified Normal:

(5) $\mathrm{SR}=\mu\left[\Phi\left(\frac{\mathrm{LTV}-\mu}{\sigma}\right)-\Phi\left(\frac{-\mu}{\sigma}\right)\right]+\frac{\sigma}{\sqrt{2 \pi}}\left[\mathrm{e}^{-\frac{\mu^{2}}{2 \sigma^{2}}}-\mathrm{e}^{-\frac{(\mathrm{LTV}-\mu)^{2}}{2 \sigma^{2}}}\right]+\operatorname{LTV}\left[1-\Phi\left(\frac{\mathrm{LTV}-\mu}{\sigma}\right)\right]$

The required data inputs for the model to be applied to a real estate collateralized portfolio of a bank include the following. The data are split into those from banks as of Year 0 , next to parameters and assumptions in the model, including the house price scenario.

Table 3.1. Data Inputs for the Advanced LGD Model Bank portfolio as of 'Year 0 '

1. LTV, ideally exposure-weighted

2. Cure rate: annual transition rate S3-2 from most recent IFRS 9 transition matrix

3. LGD (if not available, take provision coverage ratio as proxy)

\section{Model parameters}

1. House price scenario path, for residential or commercial property prices depending on portfolio type

2. Cure rate assumption under scenario

3. Cost parameter assumption (e.g. $5 \%$ )

4. Standard deviation of sales ratio distribution (e.g. $20 \%$ based on expert judgment)

The application of the model entails three steps: first, an effective sales ratio mean $\mu$ has to be found, to thereby let the model-implied LGD match the observed LGD at the bank/portfolio-level, and conditional on all other parameters for the bank portfolio (see Table 3.1). ${ }^{21}$ Once the sales ratio mean is found, it is "fixed." Second, a house price scenarioconditional LTV should be computed:

(6) $\operatorname{LTV}(t)=\operatorname{LTV}(0) \times \frac{\mathrm{HP}(0)}{\mathrm{HP}(\mathrm{t})}$

\footnotetext{
${ }^{21}$ Alternatively, one may instead set a sales ratio mean $\mu$ and imply the standard deviation $\sigma$.
} 


\section{Box 3. A Simple and an Advanced LGD Model for Real Estate-Collateralized Portfolios} (concluded)

Third, the final scenario-conditional LGD can be implied by this LTV in conjunction with equations (1)-(3). Figure 3.2 shows a numerical example, based on the Excel-based implementation of the two models as outlined in this box. An explanation of how the Excelbased solver can be used to find the sales ratio mean is embedded in the Excel file for this module, which accompanies this paper.

Figure 3.2. Numerical Example, Simple versus Advanced LGD Model

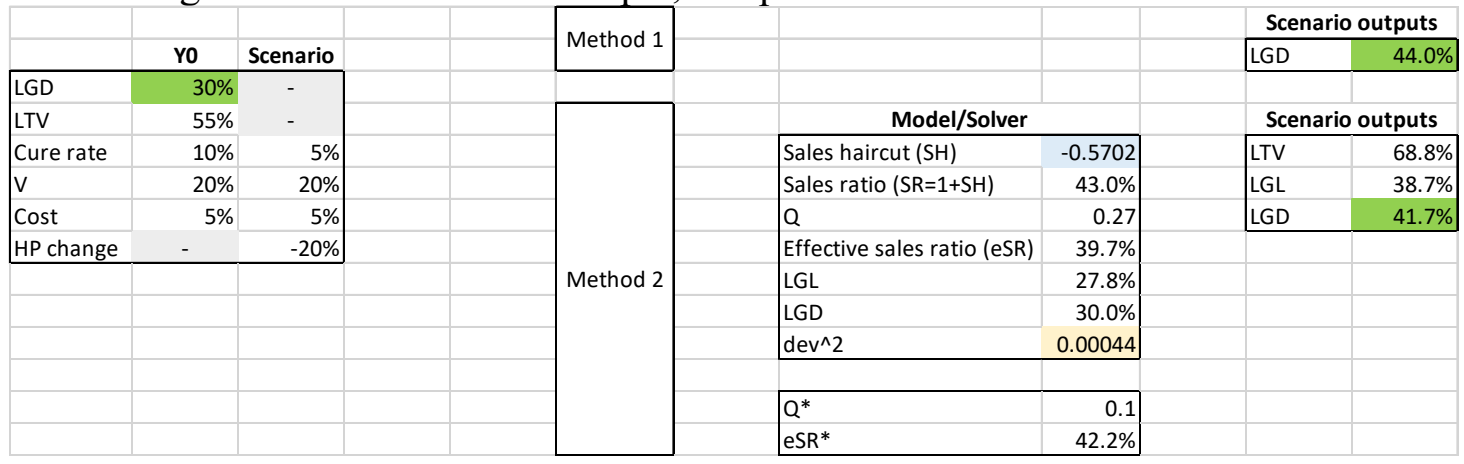

A comparison based on different combinations of initial LGDs and LTVs as of Year 0 are presented in Figure 3.3. cLTV in Figure 3.3 denotes the current LTV. The underlying assumptions are that house prices fall by 20 percent, a cure rate in Year 0 is 20 percent, falling to 10 percent in the scenario, a cost percentage of 5 percent and a standard deviation of the sales ratio at 20 percentage points. The results suggest that the "simpler" model (equation 1) results in larger scenario-conditional LGDs at low initial LGD levels, and the opposite at high levels of LGDs at the outset. It will be beneficial in general to consider the more advanced LGD model, in order to obtain a more realistic scenario-conditional LGD estimate.

Figure 3.3. Difference between Simple and Advanced LGD Model Outcome Depending on Initial LGD/LTV Starting Points
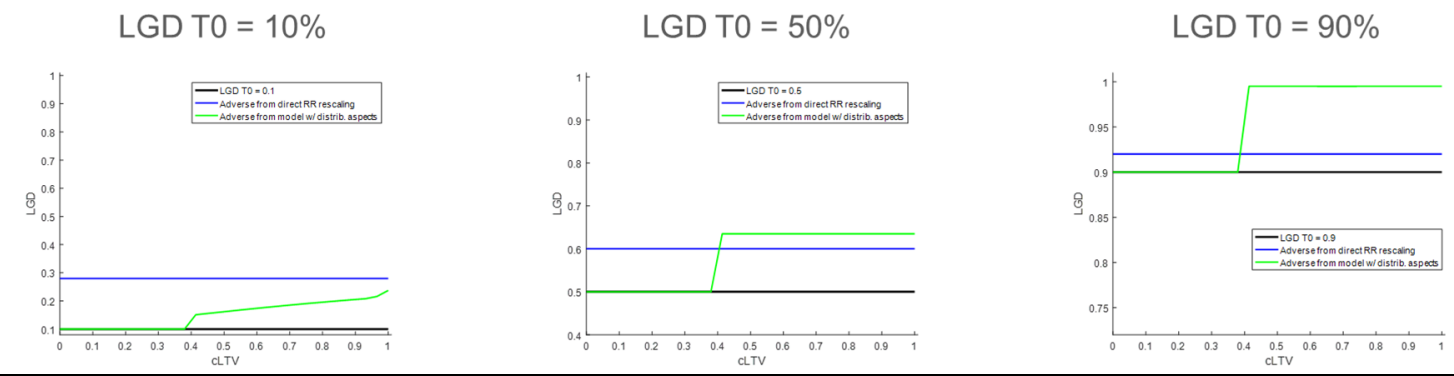

\section{E. Lifetime Expected Credit Loss Calculations}

Lifetime expected credit loss (LT-ECL) calculations are necessary because loan loss provisions for $\mathrm{S} 2$ and $\mathrm{S3}$ exposures should have a lifetime horizon, and for the performing portfolio under CECL. The lifetime horizon requires, in principle, that macrofinancial scenarios would need to be extended to the residual maturity of a portfolio under 
consideration. For example, for mortgage portfolios that tend to have long durations, for example, 15 years on average, these scenarios would translate into TM forward paths and expected losses would need to cover up to 15 years. ${ }^{22} \mathrm{We}$ consider two options for dealing with this fact: one is to employ simple assumptions about how macro-financial factors and implied risk parameters move beyond an initial scenario horizon in a stress test, which usually covers three to five years. A second option is to conduct the scenario simulations based on a macro-financial model suite explicitly farther into the future. We discuss these options in subsection F.

A lifetime ECL formula forms the starting point for the ECL calculations. The formula and the meaning of its components are explained in Box 4.

\section{Box 4. Lifetime Expected Credit Loss (LT-ECL): Formula and Components}

A LT-ECL formula can be structured as follows:

(1) $\mathrm{ECL}_{\mathrm{t}}^{\mathrm{LT}}=\sum_{\mathrm{s}=\mathrm{t}+1}^{\mathrm{M}} \frac{\mathrm{TR}_{\mathrm{s}}^{2-3, *} \times \mathrm{LGD}_{\mathrm{s}} \times \mathrm{S} 2_{\mathrm{s}-1}}{(1+\mathrm{r})^{\mathrm{s}}}$

with $\mathrm{M}$ denoting the average residual maturity of a portfolio. The lifetime ECL is measured in monetary units. The right side includes a point-in-time LGD and the relevant exposure, which is the S2 stock (or all non-defaulted exposures under CECL). The denominator of the formula involves an effective loan interest rate for discounting the ECL along the lifetime of a loan portfolio. The formula for the incremental $\mathrm{PD}$ in the numerator, denoted $\mathrm{TR}_{\mathrm{S}}^{2-3, *}$, is:

(2) $\mathrm{TR}_{\mathrm{s}}^{2-3, *}=\mathrm{TR}_{\mathrm{s}}^{2-3} \times \underbrace{\prod_{\mathrm{t}=1}^{\mathrm{s}-1} \overbrace{\left(1-\mathrm{TR}_{\mathrm{t}}^{2-3}\right)}^{\text {PiT survival probability }}}_{\text {cumulative survival probability }}$

The term $\mathrm{TR}_{\mathrm{s}}^{2-3}$ is the unconditional transition probability for $\mathrm{S} 2$ stocks, which links to the outcome of the transition matrix forecast path (Box 2). While this unconditional PD $\left(\mathrm{TR}^{2-3}\right)$ moves over the lifetime of a loan portfolio in an "unrestricted" manner, and in relation to macro-financial conditions, the incremental PD measures the PD in period $s$ conditional on not having defaulted up to period $s-1$ and approaches zero over time. ${ }^{/ 1}$ The quantitative behavior of the various probabilities involved here is depicted in Figure 4.1. As an example, the PiT PD (Figure 4.1, right char, green) has been set to a constant. It would later vary in a scenario (more on that in the section about perfect foresight).

1/ If the maturity parameter M in equation (1) were set to one, then the lifetime ECL would be a 12-month ECL. In this case, the incremental PD would equal the unconditional PD according to equation (2). If one may ignore in this case the discount factor in the denominator of equation (1), then the ECL formula would attain the standard "PDxLGDxEAD" structure.

\footnotetext{
${ }^{22}$ One may assume that the loan default probability after some time (say, five years) would be sufficiently low, so that the lifetime ECL calculations can be confined to such shorter horizon. Loan prepayments (especially in countries where fixed rate mortgages are dominant) also reduce the effective expected duration of loans. This implies that a macro scenario can be developed with a shorter horizon, which should be beneficial.
} 


\section{Box 4. Lifetime Expected Credit Loss (LT-ECL): Formula and Components (continued)}

Figure 4.1: Cumulative Survival Probability, Cumulative PD, and Point in Time (PiT) versus

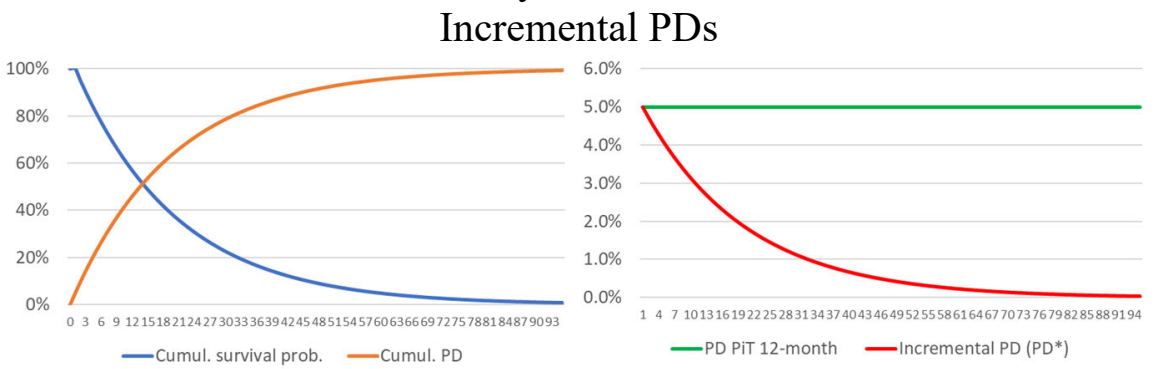

The S2 exposure term in equation (1) could be projected into the future by either employing an equation that resembles a nonlinear repayment schedule of fixed or variable rate loans, or a simplifying assumption that would stipulate a linear principal repayment path for the sake of simplicity. The ECL estimates may not be overly sensitive to this choice.

${ }^{2 /}$ If a nonlinear repayment schedule was employed, for variable rate loan portfolios specifically, then an expectation about the loan interest rate would have to be considered as well. For portfolios that are "mixed," that is, contain fixed and variable loans, two corresponding repayment schedules could be considered that could then be added together for the two portfolio components. Modeling prepayments explicitly is an option as well, the related discussion of which is beyond the scope of this paper.

\section{F. Loan Loss Provision Stock and Flow Calculations}

The ECL estimates for the exposures in the different risk categories need to be translated into accounting provision stocks. Loan loss provisions are to be held for exposures in all three stages, and they change from period to period as a function of all underlying risk parameters, including PDs (PiT and implied lifetime) and LGDs. The continuous dependence on changing risk parameters distinguishes the IAS 39 and IFRS 9 / CECL accounting regime, as under IAS 39, performing exposures were not provisioned for, ${ }^{23}$ and nonperforming exposures were a function of only the LGD (once they entered the NPL stock). ${ }^{24}$ Box 5 summarizes the formulas for computing provision stocks and flows under IFRS 9 and CECL, and as a comparison as well for the incurred loss concept under the previous IAS 39 regime.

In a stress test application involving an assumed adverse scenario, the IFRS 9- and CECL-implied loan loss provision flows can be expected to be more front-loaded than under IAS 39. Under IFRS 9, a "cliff effect" results from the 12-month provision horizon set for S1 and the lifetime ECL horizon for S2 exposures, with the latter tending to increase significantly in year one of an adverse scenario. This effect is exemplified based on artificial

\footnotetext{
${ }^{23}$ With the exception of "Incurred But Not Reported" (IBNR) provisions which were typically used as the general provisions accounting for non-incurred/non-reported losses.

${ }^{24}$ Provision stocks in addition change due to changing exposure stocks, which are driven in turn by principal repayment flows, new loan issuance, and write-offs.
} 
data in Box 5 and the accompanying ECL Model Suite, and replicates the impact pattern as reported, for example, by the $\mathrm{BoE}$ in its stress test 2018 results publication. ${ }^{25}$

The provision stock and flow calculations can be refined by distinguishing the risk parameters, for instance, in terms of LGDs, for the different cross-stage migrations. An example of a more refined provision methodology can be found in the EBA/ECB/SSM stress test $2018 .{ }^{26}$ From a top-down solvency analysis perspective, one should carefully weigh the costs and benefits of working with more granular model structures, as the implied additional burden in terms of data needs and possibly increasingly impaired data quality may hamper the robustness of the final provision estimates.

\section{Box 5. Loan Loss Provision Stock and Flow Calculations}

For S1 exposures under IFRS 9, the provision stocks are to equal the 12-month expected credit loss, that is:

(1) $\mathrm{PROV}_{\mathrm{t}, \mathrm{S} 1}=\mathrm{ECL}_{\mathrm{t}, \mathrm{S} 1}=\mathrm{TR}_{\mathrm{t}+1 \mid \mathrm{t}}^{13} \times \mathrm{LGD}_{\mathrm{t}+\mathrm{H} \mid \mathrm{t}} \times \mathrm{S}_{\mathrm{t}}$

This resembles the "PDxLGDxEAD" structure. Any change in the underlying risk parameters would imply a provision flow and hence an impact on the $\mathrm{P} \& \mathrm{~L}$. The term $\mathrm{TR}_{\mathrm{t}+1 \mid \mathrm{t}}^{13}$ is the expected default rate for $\mathrm{S} 1$ exposures conditional on end of period-t information for the following year. The $\mathrm{LGD}_{\mathrm{t}+\mathrm{H} \mid \mathrm{t}}$ term has a $\mathrm{t}+\mathrm{H}$ to denote the fact that the LGD is meant to be forward-looking beyond a one-year horizon if the expected time until collateral can be sold is more than 1 year. For S2 exposures, the lifetime ECL formula (Box 4) becomes relevant, that is:

(2) $\mathrm{PROV}_{\mathrm{t}, \mathrm{S} 2}=\mathrm{ECL}_{\mathrm{t}, \mathrm{S} 2}^{\mathrm{LT}}=\sum_{\mathrm{s}=\mathrm{t}+1}^{\mathrm{M}} \frac{\mathrm{TR}_{\mathrm{s}}^{23, *} \times \mathrm{LGD}_{\mathrm{s}+\mathrm{H} \mid \mathrm{s}} \times \mathrm{S} 2_{\mathrm{s}-1}}{(1+\mathrm{r})^{\mathrm{s}}}$

For S3 exposures, provision stocks are meant to cover the portion of the defaulted exposures that will likely not be recoverable, that is:

(3) $\mathrm{PROV}_{\mathrm{t}, \mathrm{S} 3}=\mathrm{ECL}_{\mathrm{t}, \mathrm{S} 3}=\mathrm{LGD}_{\mathrm{t}+\mathrm{H} \mid \mathrm{t}} \times \mathrm{S}_{\mathrm{t}}$

The total provision stock equals the sum of the stage-specific provision stocks:

(4) $\mathrm{PROV}_{\mathrm{t}}=\mathrm{PROV}_{\mathrm{t}, \mathrm{S} 1}+\mathrm{PROV}_{\mathrm{t}, \mathrm{S} 2}+\mathrm{PROV}_{\mathrm{t}, \mathrm{S} 3}$

The loan loss provision flow is then the change in the stock, adjusted for write-offs:

(5) PROVFLOW $_{t}=\Delta \mathrm{PROV}_{t}+\mathrm{WRO}_{\mathrm{t}} \times \mathrm{LGD}_{\mathrm{t}} \times \mathrm{S}_{\mathrm{t}-1}$

The adjustment term related to the write-offs (inclusive of asset sales where relevant) accounts for the fact that exposures that are written off, and whose provision stock is falling for that reason, which should be residual net-equity neutral. The way the adjustment term is designed involves the assumption that the LGD estimate, based on which a provision stock had been set just before the write-off, equals the realized LGD upon the collateral sale for the exposures that are written off.

\footnotetext{
${ }^{25}$ See BoE (2018), Box 1, page 11, Chart A.

${ }^{26}$ See EBA (2018a), "2018 EU-Wide Stress Test”, Chapter 2.4. As just one example, there is a distinction between the LGD for S1 and S2 financial assets, which we do not consider in Box 5.
} 


\section{Box 5. Loan Loss Provision Stock and Flow Calculations (continued)}

Under the previous IAS 39 accounting regime, only exposures that are now designated as S3 (nonperforming exposures) were to be provisioned for on an incurred loss basis. Under IAS 39, the provision stock formula in equation (4) would exclude the terms related to the S1 and S2 stocks. The provision flow expression, equation (5), would not change.

Based on a numerical example that is embedded in the tool suite that accompanies this paper (provision stock and flow module), a comparison of the P\&L losses under IAS 39, IFRS 9, and CECL may often appear as depicted in Figure 5.1. This example is based on an underlying adverse scenario. One can see that the loss rates under the IFRS 9 regime are significantly higher in (front-loaded to) year one (cliff effects). Disregarding second round macroeconomic effects, the cumulative losses over a longer adverse period would be the same under all accounting regimes. The only difference they make is in terms of the timing of recognizing the losses.

Figure 5.1. Numerical Example of Loan Loss Provision Flows under IAS 39 and IFRS 9

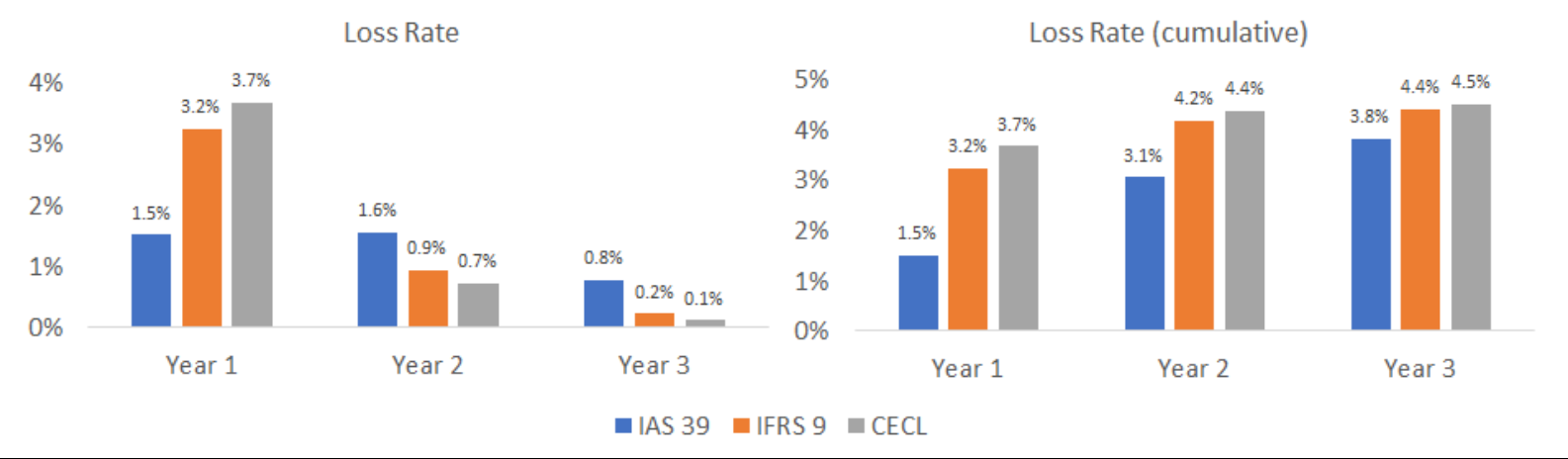

Full lifetime ECL for a combined S1+S2 portfolio can be a useful benchmark for topdown stress testers. The rationale for employing a full lifetime ECL approach akin to CECL for top-down stress testing in IFRS 9 regimes can be motivated based on at least three arguments: (1) for the purpose of comparing and learning about the effective difference that the S1/S2 differentiated provisioning scheme makes in practical stress test applications compared to a full lifetime provisioning scheme; (2) importantly, to require less data, both in terms of historical and starting point information; and (3) not requiring a transition matrix model approach implies less model risk, and hence fostering robustness.

\section{The top-down stress testing modeling strategy under a full lifetime ECL approach can} still follow in many respects the concepts laid out in this paper. The transition matrix model approach would become obsolete as the transition matrix reduces down to a $2 \times 2$ matrix, hence requiring only the modeling of the PiT PD, say, with a 12-month horizon, using a standard fractional logit approach. The LGD model strategy can involve the modules as described in Section IV.C and Box 3. The lifetime PD calculations (Section IV.D and Box 4) would be simpler: equation (1) in Box 4 would apply to the total performing exposure stock instead of only to S2, and equation (2) in Box 4 would apply to the overall PD of the performing exposure, instead of only to the transition probability $\mathrm{TR}^{2-3}$. The provisioning calculations (Section IV.E and Box 5) would be simplified, since equation (1) in Box 5 would become obsolete, and Box 5's equation (2) be applicable to the combined S1 and S2 stock instead of only S2. When using a CECL approach in an IFRS 9 regime, it is important, 
however, to be wary about the difference in the model-implied Year 0 provision stocks compared to the banks. The banks' year 0 provision stocks would be smaller because S1 stocks are provisioned for based on a 12-month horizon, not a lifetime horizon. CECL stress test provision flows should be expressed with reference to the model-implied Year 0 provision stocks in this case.

\section{G. Interplay Between Accounting and Capital Regulation}

The interplay between regulatory capital and accounting provisions arises because both components are to shield future credit losses. Loan loss provisions and residual net equity capital are to serve as a buffer for expected and unexpected losses, respectively. ${ }^{27}$ Since Basel II, the IRB approach to credit risk measurement is designed so that it is compatible with a 12-month ECL horizon based on regulatory risk parameters (Gordy 2003, BCBS 2005). The set of regulatory risk parameters includes a through-the-cycle (TTC) PD and a downturn LGD.

The regulatory treatment of accounting rules considers provisioning shortfall or excess. For IRB portfolios, the "IRB shortfall" rule is considered: if regulatory EL exceeds accounting provision stocks, then the difference is subtracted from CET1. If it falls short of an accounting provision stock, then the difference may be added back to Tier 2 capital subject to a limit of 0.6 percent of credit risk RWA and regulatory prior approval. For STA exposures, general provision stocks can be added back to Tier 2 capital subject to a limit of 1.25 percent of credit risk RWA.

The regulatory treatment of accounting provisions under IFRS 9 and CECL has been suggested to not change for the time being. Following an industry consultation by the BCBS in October 2016 (BCBS 2016), the BCBS's conclusion in March 2017 (BCBS 2017) was to not make any adjustments to the current regulatory treatment of accounting provisions until further notice. The question arises as to whether the treatment should change given that the accounting provision mechanism has been redesigned materially. ${ }^{28}$ Regarding the distinction between regulatory general and specific provisions for STA exposures, the question arises as to whether the concept of general provisions still has any role to play. General provisions resemble a residual capital philosophy, to shield unexpected rather than expected losses. On the accounting side, no such distinction between general and specific provisions is to be made. It has been suggested, indeed, that all accounting provisions under IFRS 9 are to be interpreted as specific provisions (EBA 2017). The Basel Committee

\footnotetext{
${ }^{27}$ We call the sum of loan loss provisions and residual net equity,"gross equity."

${ }^{28}$ Such discussion is beyond the scope of this paper.
} 
meanwhile put this discussion on hold and leaves it to individual jurisdictions to map IFRS 9 provisions to general and specific provisions.

For IRB portfolios, one can establish a link between the regulatory risk parameter scenario paths and the PiT risk parameters on the accounting side. ${ }^{29}$ The rationale for doing so is that a rise in PiT risk parameters under an adverse stress test scenario, if significant enough and prevailing for a reasonably long period (for example three to five years), will possibly call for an upward adjustment to regulatory risk parameters as well, for the dual sake of consistency and conservatism in a stress test.

When considering whether regulatory risk parameters are to be made a function of PiT risk parameters in a scenario, one should be mindful of the nature of the underlying scenario narrative. A cyclical scenario may call for less of a need to pass PiT risk parameter stress on to regulatory risk parameters, because by nature of a cyclical scenario it would entail a more short-lived, confined time window for an assumed recession. Structural shock scenarios, possibly involving severe external shocks for example for trade-oriented countries, on the other hand, may imply severe downturns that are rather state-independent, longerlived, and hence be warranting a dependence of regulatory on PiT risk parameters.

The way the regulatory risk parameters are steered as a function of PiT parameters is often ad hoc, implying a model risk of its own kind. For example, when considering either five- or 10-year windows over which historical averages of PiT parameters are taken, for obtaining TTC PDs. Such time window choice is ad hoc, and the implied sensitivity of through-the-cycle (TTC) PDs to PiT PDs in a scenario, hence, as well. With such caveats in mind, Box 6 presents a simple methodology for establishing a link between regulatory and PiT risk parameters, while emphasizing how that link would be set up in an IFRS 9-specific accounting environment.

\footnotetext{
${ }^{29} \mathrm{We}$ assume here that it is possible to map the accounting exposures classes with regulatory exposure classes.
} 


\section{Box 6. Risk Weighted Assets: Linking Regulatory Risk Parameters (IRB) to PiT Risk Parameters (Accounting)}

For obtaining a scenario-sensitive path of regulatory PDs for an IRB portfolio, one may link it to the scenario-conditional corresponding PiT PD path. Since there is no distinction between S1 and S2 from a regulatory perspective, one would first compute an exposure weighted average PiT PD based on the transition rates TR1-3 and TR2-3 along the scenario horizon:

(1) $\mathrm{PD}_{\mathrm{t}+1 \mid \mathrm{t}}^{\mathrm{PiT}}=\frac{\mathrm{S} 1_{\mathrm{t}} \times \mathrm{TR} 13_{\mathrm{t}+1 \mid \mathrm{t}}+\mathrm{S} 2_{\mathrm{t}} \times \mathrm{TR} 23_{\mathrm{t}+1 \mid \mathrm{t}}}{\mathrm{S} 1_{\mathrm{t}}+\mathrm{S} 2_{\mathrm{t}}}$

This PiT PD forward path one can now link to the regulatory, TTC PD path:

(2) $\mathrm{PD}_{\mathrm{t}+1 \mid \mathrm{t}}^{\mathrm{TTC}}=\operatorname{logit}{ }^{-1}\left(\operatorname{logit}\left(\mathrm{PD}_{\mathrm{t} \mid \mathrm{t}-1}^{\mathrm{TTC}}\right)+\alpha \times \Delta \operatorname{logit}\left(\mathrm{PD}_{\mathrm{t}+1 \mid \mathrm{t}}^{\mathrm{PiT}}\right)\right)$

The logit and inverse logit functions are involved to guarantee that the TTC PD never leaves the [0-1] interval..$^{30}$ The term $\alpha$ is a smoothing parameter that should be set to a value between 0 and 1 , for example, to 0.75 . Its purpose is to retain the TTC concept for the PD, and in turn to not cause excessive fluctuations (eventually more procyclicality) if a full "passthrough" from PiT PD to TTC PD changes was instead considered. A "full pass-through" would amount to setting $\alpha$ to 1 . The $\alpha$ parameter can be informed when one knows about the banks' time window that they employ for computing moving averages of PiT parameters to obtain the TTC measure; otherwise, $\alpha$ would require a judgmental setting and warrant sensitivity analyses in this case.

For the regulatory LGD, a downturn (DT) LGD, the following link can be considered:

(3) $\mathrm{LGD}_{\mathrm{t}+1 \mid \mathrm{t}}^{\mathrm{DT}}=\max \left(\mathrm{LGD}_{\mathrm{t}=0}^{\mathrm{DT}}, \mathrm{LGD}_{\mathrm{t}+1 \mid \mathrm{t}}^{\mathrm{PiT}}\right)$

It is the maximum of the downturn LGD from the outset observed for a bank portfolio and the PiT LGD, which may or may not exceed the downturn LGD either at the outset or along the scenario horizon. The resulting regulatory PD path from equation (2) and the downturn LGD path from equation (3) could now be used to feed the Basel risk weight formulas. ${ }^{31}$

\section{Perfect Foresight Versus (Few) Multiple Scenarios Versus Monte Carlo SIMULATIONS}

IFRS 9 requires the use of multiple macroeconomic scenarios, for their implied ECL estimates to be weighted by the corresponding scenario probabilities. Paragraph 5.5 .17 in IASB (2014) stipulates that the ECL estimates are to reflect an "unbiased and probabilityweighted amount that is determined by evaluating a range of possible outcomes." This

\footnotetext{
${ }^{30}$ The logit function has the form: $\operatorname{logit}(\mathrm{x})=\ln (\mathrm{x} /(1-\mathrm{x}))$. The inverse logit function (Sigmoid function) has the form: logit ${ }^{-}$ ${ }^{1}(\mathrm{y})=\exp (\mathrm{y}) /(1+\exp (\mathrm{y}))$. As one alternative, a standard normal and inverse standard normal distribution function could be used instead. As a second alternative, an absolute change could be considered, in which case a max-min-based cap and floor at 1 and 0 should be considered around the equation. All three options generally result in similar quantitative outcomes.

${ }^{31}$ See BCBS 2005, “An Explanatory Note on Basel II IRB Risk Weight Functions.”
} 
implies that at least two scenarios are to be considered. The open questions are how such scenarios should be constructed and how the weights assigned to them should be set. The banking industry so far appears to adopt a rather ad hoc and judgmental approach in both respects. $^{32}$

"Perfect foresight" means that only one scenario is considered, for example, an adverse scenario, which is assumed to materialize with 100 percent weight (probability). This assumption would not be compatible with the IFRS 9 requirements, hence for accounting provisioning purposes, banks are not allowed to employ such an approach. For top-down stress testing, such an approach can be considered, as institutions that conduct them are not bound by the accounting rules. The BoE and the ECB/EBA/SSM did employ the perfect foresight assumption in their recent stress tests (BoE 2017/2019, EBA 2018a/b, SSM 2019). The reliance on only one scenario implies the risk of having hand-picked a scenario that may not properly address the risks and vulnerabilities of a macro-financial system, including its financial institutions, at a current juncture. It relates to the notion of scenario uncertainty. ${ }^{33}$

There are two strategies for reaching a lifetime horizon when it is notably longer than conventional stress test horizons of two to five years. A first strategy is to develop conditional forecasts of the PiT risk parameters for a time window up to the average residual maturity of a portfolio, that is, in particular for the TM paths (Box 2). This requires assumptions for the paths of all relevant macro drivers. Second, one can employ simplifying assumptions, as depicted in Figure 10. The baseline and adverse scenario paths for the TM would be projected only up to, for example, a five-year horizon, and subsequently be assumed to remain steady under the baseline and to revert back under the adverse toward the baseline scenario, over a self-defined time horizon, for example, eight to 10 years. The endpoint of the scenarios may also be set to the long-term average transition matrix (including the two default rates), in which case one would establish an anchor point in regulatory TTC parameters effectively.

Nonlinearities are conceived to matter, and the multiple scenarios requirement of IFRS 9 and CECL is meant to help account for those. The high-level guidance of IFRS 9 in this respect is not particularly concrete. Any ad hoc choice of scenarios or setting of weights would not, in our opinion, make it likely that specific nonlinearities in the relation between macro-financial variables and bank risk metrics, including expected losses, could be properly identified and captured.

\footnotetext{
32 The information provided to the authors of this paper by selected consultancy firms suggested that the majority of banks currently considers three scenarios as a standard setting, with a small, single-digit percentage of banks using four scenarios. Scenarios may be calibrated either based on banks' in-house expertise and models (if a research department is present, for instance) or be purchased from external providers that specialize in macro-financial scenario design. Scenario weights are set in an ad-hoc rather judgmental manner, according to the feedback obtained.

${ }^{33}$ There is a related literature on worst case search techniques in stress testing, which is beyond the scope of this paper.
} 
To account for scenario uncertainty and to increase the likelihood that relevant nonlinearities are captured, Monte Carlo-type simulations based on integrated macrofinancial stress test model suites can be useful. A simulation-based approach should account for macro-financial feedback, that is, a two-way relationship at most between real activity and credit growth metrics and allow for considering all fundamental sources of uncertainty in an econometric sense, that is, residual uncertainty, coefficient uncertainty, and model uncertainty. Scenario uncertainty in turn is a function of all three fundamental sources of uncertainty, and in addition, it is a function of the (possibly not entirely relevant) scenario shock narrative that scenario designers may choose. Box 7 presents an exemplary simulation that illustrates how a set of self-defined, hand-picked scenarios and corresponding weights may deviate from the outcome of a Monte Carlo-type simulation, in a setting in which certain nonlinearities are known to be present in the system. The suggestion is not to necessarily conduct such stochastic simulations as part of a regular tool-suite for IFRS 9-/CECLcompatible stress testing but is meant instead to highlight some conceptual questions that arise about scenario choice and weight setting.

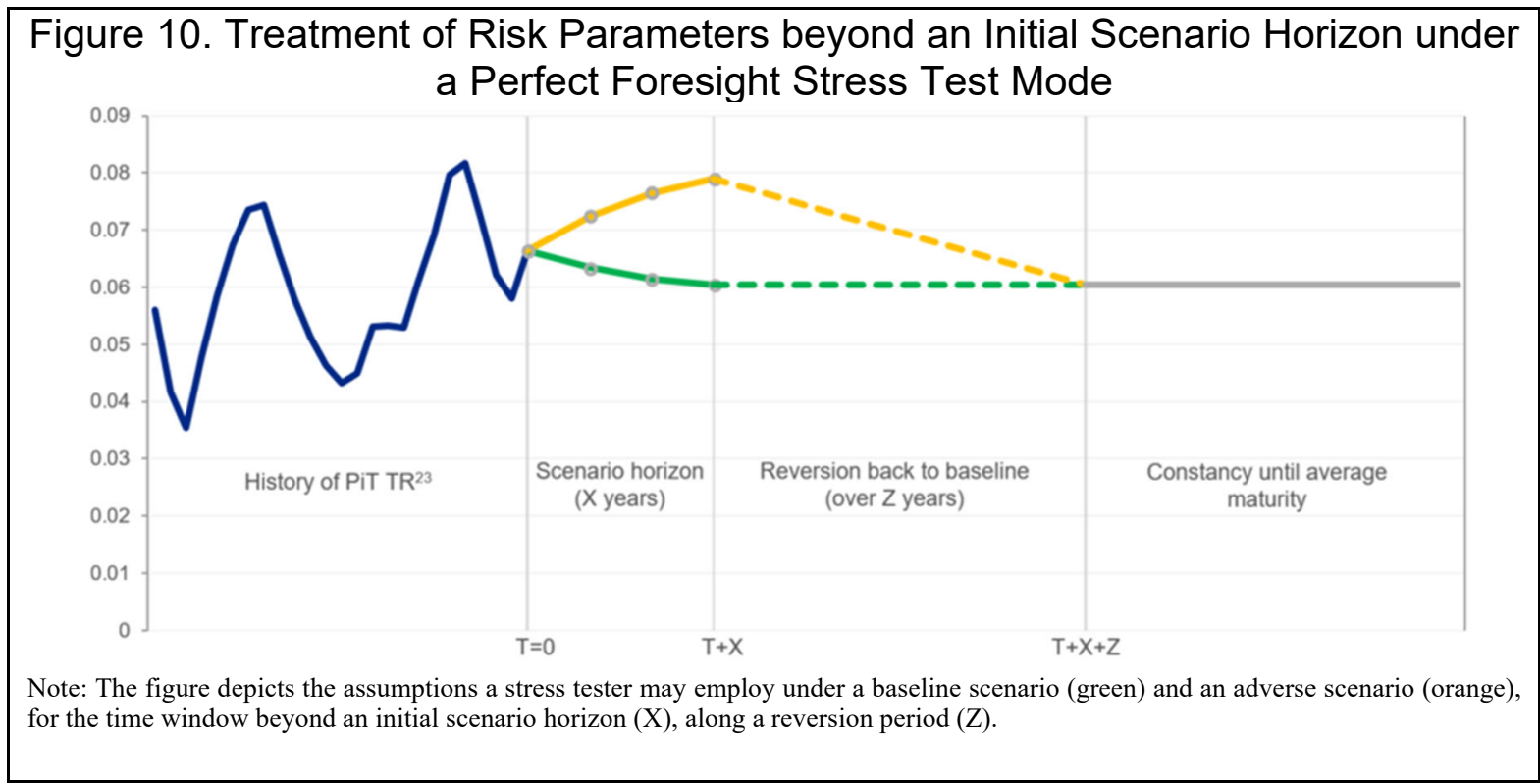




\section{Box 7. Monte Carlo-based Lifetime Expected Loss Distributions Versus Self-Set Scenarios and Weights}

We set up an exemplary model suite for a hypothetical Stage 2 portion of a loan portfolio of a bank or banking system. It has the following components: first, a trivariate VAR with annual frequency (1988-2018, 31 obs.), containing real GDP (natural log differences YoY, lnYoY), nominal house prices (lnYoY), and a PD for the private sector (logit levels). ${ }^{11}$ Figure 7.1 shows the historical data. Second, the simpler version of the two structural LGD models (Box 3, equation 1) is connected to the house price growth variable. Third, a linear repayment scheme for the S2 exposure is considered. Fourth, the lifetime loss calculation scheme (Box 4, equations 1 and 2) is connected to the system.

Figure 7.1. Historical Data Involved in VAR and Connected LT-ECL Simulator
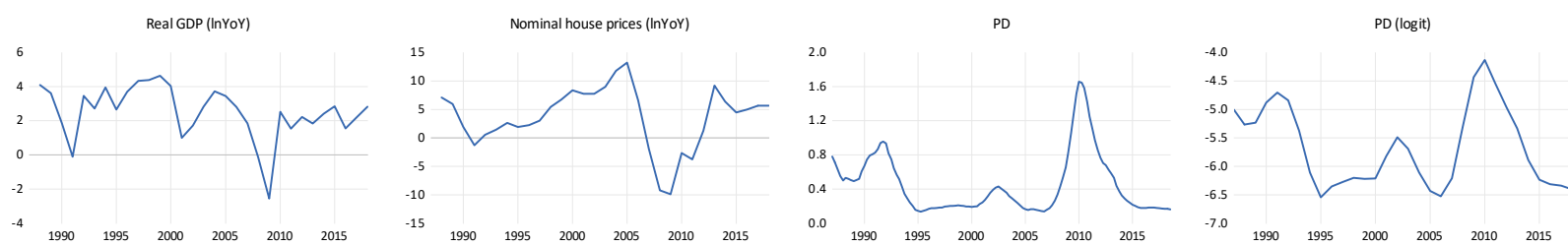

Notes: The sample covers the 1988-2018 period (31 obs.). The PD is displayed in level percentage and in logit format (the latter of which is included in the trivariate VAR along with real GDP and nominal house price growth).

A stochastic simulation based on the VAR and the connected model set around it is conducted. Two simulation schemes are considered: the first accounting for residual uncertainty, the second for both residual and coefficient uncertainty stemming from the VAR. ${ }^{2}$ We simulate 2,000 paths under both schemes for all variables in the system, including the variables from the VAR, and via the connected structural elements the LGD, the incremental and lifetime PDs, and the lifetime ECL ratio. The scenario horizon was set to 10 years, reflecting the assumption that the hypothetical underlying portfolio would have an average residual maturity of 10 years. For the LGD module, the relevant horizon is assumed to be the first three years of the 10-year time span, reflecting the assumption that the average time to sale of collateral equaled three years. The starting point LGD is set to 50 percent, and the interest rate for discounting is set at 1 percent and treated as exogenous throughout the simulation ( $r$ in Box 4, equation 1). ${ }^{13}$

Figure 7.2 shows the resulting distribution of the LT-ECL ratio at the outset of the horizon which is consistent with the simulated paths of all variables. The account for coefficient uncertainty on top of residual uncertainty implies an additional widening of the distribution. The mean and median LTECL ratio shift upward to an extent and the skewness of the distribution increases markedly.

Based on the VAR, we produce a baseline point forecast path and two impulse response-based alternative paths - one on the upside and one on the downside - by shocking GDP growth at the $10^{\text {th }}$ and $90^{\text {th }}$ percentile of the GDP growth VAR equation's residuals, considering a generalized impulse response scheme (Koop et al. 1996).

1/ Since the assessment in this box is meant to be illustrative and for the purpose of deriving some high-level conceptual conclusions, there is no need to tell which country's data was used. The PDs were sourced from Moody's KMV for the nonfinancial corporate sector. We use them here in conjunction with the LGD module as if they were an LGD for a real estate collateralized portfolio. In practice, one would clearly not make such assumptions. It is purely for the sake of a conceptual discussion in relation to scenario weights in this box.

2/ A parametric bootstrap (assuming multivariate Normality for the three VAR equations' residuals) is used for the simulation scheme accounting for residual uncertainty. A pseudo-data resampling method to obtain alternate coefficient vectors is considered when accounting for coefficient uncertainty, in conjunction with the residual bootstrap.

3/ An interest rate variable could be included in the VAR to endogenize the discount rate. Regardless, IFRS 9 stipulates that a contractual interest rate at the outset of the scenario horizon is to be used for discounting. Whether we would endogenize the interest rate or not would not change the conceptual conclusions that we draw later in this box. 


\section{Box 7. Monte Carlo-based Lifetime Expected Loss Distributions Versus Self-Set Scenarios and Weights (continued)}

Figure 7.2. LT-ECL Distributions Accounting for Different Sources of Uncertainty

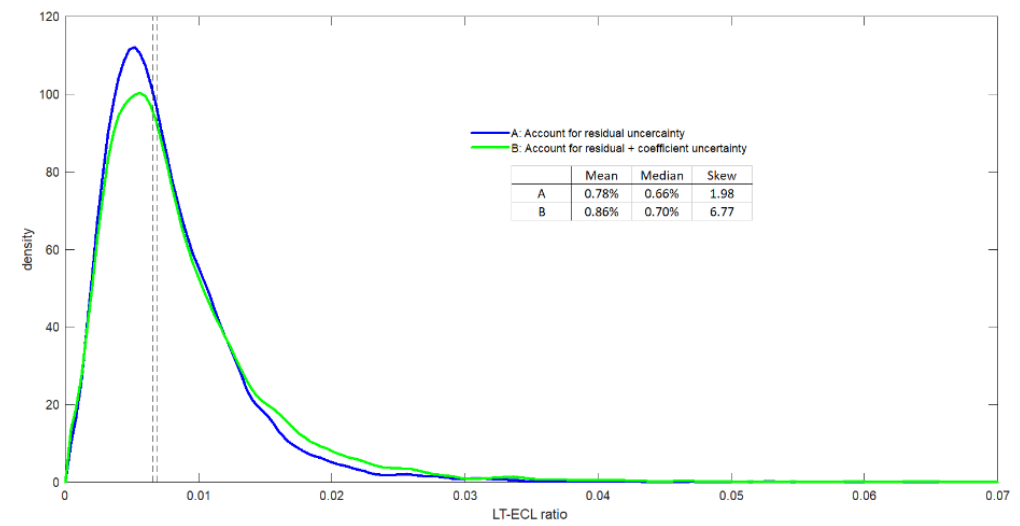

Notes: On the horizontal axis, 0.01 denotes 1 percent. The two vertical dashed lines denote the medians of the distribution under $\mathrm{A}$ and $\mathrm{B}$.

Figure 7.3 shows the resulting paths for the variables from the VAR in the system.

Figure 7.3. "Hand-picked" Scenario Paths: Baseline, Upside, and Downside Scenario
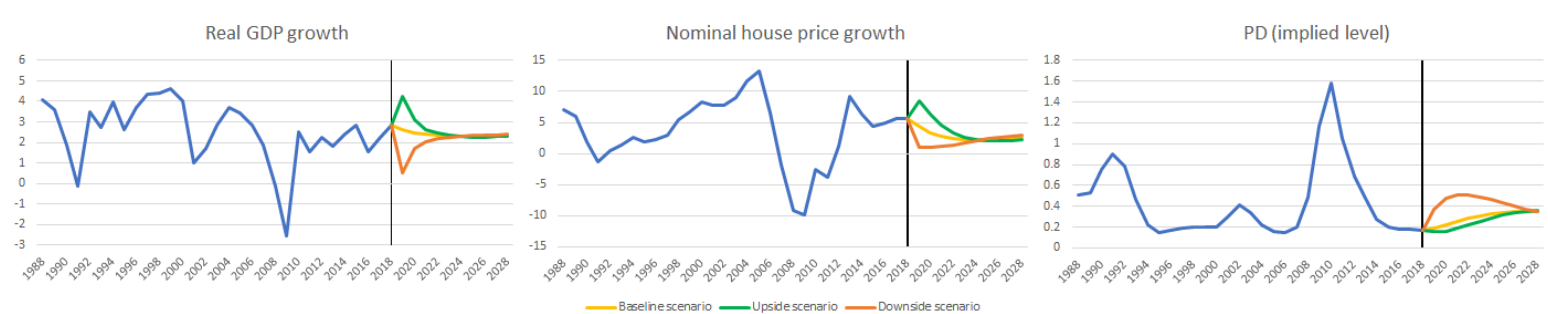

We translate the three scenarios into three LT-ECL ratio point forecasts and position them in the simulated LT-ECL distribution; considering now only the distribution that reflected both residual and coefficient uncertainty. Figure 7.4 shows the result.

Figure 7.4: Hand-picked Scenario-Implied LT-ECL Ratios Positioned in Simulated LT-ECL Distribution

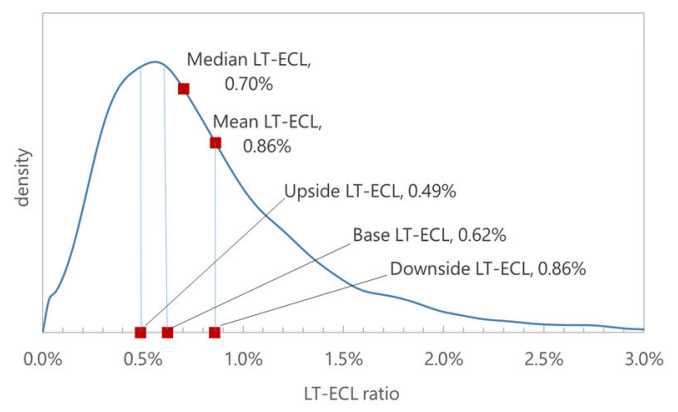

First, we see that the baseline point forecast of the LT-ECL ratio does not equal either the mean or median of the simulated LT-ECL distribution. The baseline point estimate ( 0.62 percent) falls short of all mean and median estimates from both simulation types (see means and median in Figure 7.2). The mean LT-ECL under distribution B in Figure 7.2 so happens to be close to the downside scenarioimplied point estimate (both at about 0.86 percent). While the up- and downside scenario-implied LTECL point forecasts surround the distribution's mean, we suspect that this may not always be the case, depending on the assumed severity of the initial up- and downside scenarios as well as on the strength of the underlying nonlinearities in the data and models. 


\section{Box 7. Monte Carlo-based Lifetime Expected Loss Distributions Versus Self-Set Scenarios and Weights (continued)}

A set of three weights can now be considered to obtain a weighted average of the three-point forecast path-based LT-ECL ratios; at 0.49, 0.62 , and 0.86 percent for the upside, baseline, and downside scenario, respectively. Figure 7.5 illustrates that there are infinitely many weight combinations ${ }^{14}$ that can be picked that imply a weighted average that would match the "true" LT-ECL ratio, with the latter taken here as the median LT-ECL ratio from the simulated distribution (0.7 percent).

Figure 7.5. Spectrum of Weights on Three Hand-Picked Scenarios that Would Imply Matching the Simulation-Based "True" LT-ECL Estimate

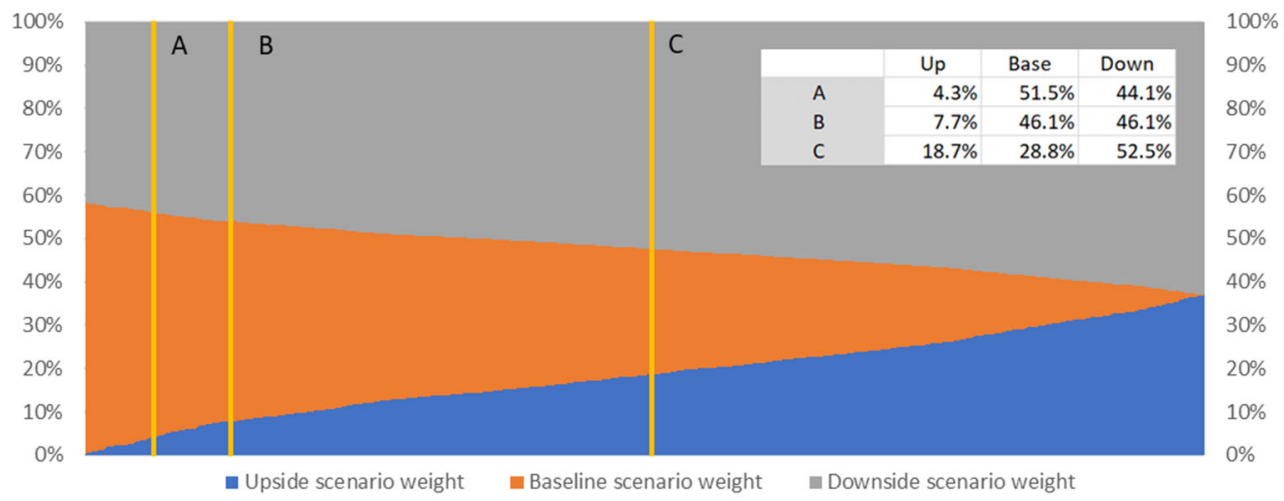

Notes: "B" denotes the point where the weight on the baseline scenario is the maximum the last time (moving from the left end toward the right of the distribution of weights). "A" represents the average of the weights from the left end up to "B." "C" represents the average of the weights along the entire range from the left to the right of the picture. Point "B" and the range to the left of " $\mathrm{B}$ " contains weight combinations that one may find useful as the baseline weight exceeds the weights on the up- and down-side scenarios. Yet, there is otherwise nothing too special about the weight sets as indicated by "A," $\mathrm{B}$," and "C."

We conclude:

1. The weight choice for three (or more) hand-picked scenarios will always remain entirely ad hoc. Tying the weights to scenario probabilities, for example, related to the impulse response shock probabilities does almost surely not result in a weighted average LT-ECL ratio that comes close to a "true" LT-ECL of a portfolio. Hence, informing the weights based on such probabilities is problematic (non-sensical).

2. The LT-ECL can be obtained by considering stochastic simulations based on an integrated model suite that contains the relevant macro drivers and structural and/or econometric satellite models for deriving the LT-ECL eventually. Once a simulation scheme is considered, there is no need any longer to consider hand-picked scenarios and their corresponding (indeterminate) weights. An integrated model suite would in practice be more refined than the one presented in this box, which was on purpose simplistic and purely for the sake of a conceptual illustration.

3. LT-ECL distributions are likely markedly skewed, and accounting for all sources of uncertainty that stem from an underlying simulation apparatus, if used in practice, is warranted to not underestimate the width and skewness of the distribution. Numerous nonlinearities in an underlying model suite - reflecting relevant nonlinearities in reality — would drive such a non-normal, skewed shape of the LT-ECL distribution.

4. As long as practitioners do not employ stochastic simulation-based methodologies, but handpicked scenarios and self-set weights, the accounting regime based on the latter scheme is bound to imply a notable risk of "ad hoc-ness."

${ }^{4 /}$ On a range whose left and right ends are specific to the numerical example as presented here. 


\section{EXEMPLARY IFRS 9 DATA TEMPLATES}

Various data need to be collected at the bank-portfolio level for a credit risk modelsuite, as presented in this paper, to be operationalized. Banks' Year 0 stock-balance sheet position need to be captured, through a template structure as exemplified in Figure 11. In addition, historical stocks of exposures in the three stages, along with the corresponding cross-stage flows, write-off flows, and new business flows, need to be collected, as exemplified in Figure 12. ${ }^{34}$ The financial asset stocks and flows are recorded here in monetary units (for example, USD, EUR), based on which the TMs with percentages can be computed by dividing time-t flows by end-of-previous period ( $\mathrm{t}-1)$ stocks.

It is important to define the staging criteria for the cross-stage flows when considering a data collection comprising a large set of banks. One option is to instruct banks to employ their own staging criteria set and generate the exposure stocks and flows accordingly. A second option is to define a common set of criteria and instruct banks to report according to those. The first option may imply a significant burden for stress testers if the aim is to adapt the bank-specific criteria set also under a top-down stress test exercise, which might not be practical or beneficial. The value in collecting the historical transitions in line with banks' own staging criteria is in turn questionable as well.

A practical compromise solution can lie in letting banks report exposure stocks and flows based on their own staging criteria, while a simplified common staging criteria set can be assumed under a stress test. The use of a common staging criteria set under a stress test, despite historical data reflecting banks' own criteria, should be a reasonable approximation - and not result in major deviations between scenario-conditional stress test outcomes and how banks' losses may behave if that scenario were to realize - the reason being that different staging criteria likely correlate strongly in practice. For example, the reference to PDs (for instance, Merton-type model-based), changes in ratings, changes in $\mathrm{CDS}$, and so on all correlate to a notable extent, for related rules to suggest similar staging dynamics as well.

For a retrospective collection of staged exposure data before January 2018, regulatory exposure classification systems can be useful. Regulatory exposure classifications in numerous countries consider grouping loan exposures into categories such as performing, substandard, doubtful, and loss. While the precise criteria sets behind such classifications differ in their details across jurisdictions, they may be suitable and close enough in rationale to the relative change in risk philosophy that IFRS 9 requires for the staging process. The groups may need to be bundled, for example, for performing to correspond to Stage 1, substandard and doubtful jointly as Stage 2, and "loss" as Stage 3. In the future, the need to refer to historical regulatory exposure stock and flow data may vanish, as direct IFRS 9 accounting-based data would be accrued over time.

\footnotetext{
${ }^{34}$ The full templates are available from the authors on request, as are the model elements presented in the earlier sections.
} 
Figure 11. Balance Sheet Stocks as of Year 0

\begin{tabular}{|c|c|c|c|c|c|c|c|c|}
\hline & & & & & & & FI1 & \\
\hline & & Stocks a & is of end-x & & Av. residual & & STA & If \\
\hline & & & & On-BS & maturity in & On+off-BS & On+off-BS & On+off-BS \\
\hline & & & Nonfinancial corporate & & & & & \\
\hline & & & of which SME & & & & & \\
\hline & & & Financial corporate & & & & & \\
\hline & & Loans (domestic) & Household mortgages & & & & & \\
\hline & & & Consumer credit and other retail loans & & & & & \\
\hline & & & Sovereign & & & & & \\
\hline & Amortized & Foreign loans (to & $\begin{array}{l}\text { Other } \\
\text { tall) }\end{array}$ & & & & & \\
\hline & cost & Bonds & Sovereign & & & & & \\
\hline & & $\begin{array}{l}\text { Bomes } \\
\text { (domestic) }\end{array}$ & Nonfinancial corporate & & & & & \\
\hline & & & $\begin{array}{l}\text { Financial corporate } \\
\text { Sovereign }\end{array}$ & & & & & \\
\hline & & Bonds & Nonfinancial corporate & & & & & \\
\hline & & & Financial corporate & & & & & \\
\hline & & Other & & & & & & \\
\hline Stage 1 & & & $\begin{array}{l}\text { Nonfinancial corporate } \\
\text { of which SME }\end{array}$ & & & & & \\
\hline & & & Financial corporate & & & & & \\
\hline & & $\begin{array}{l}\text { Lans } \\
\text { (consolidated) }\end{array}$ & Household mortgages & & & & & \\
\hline & & & Consumer credit and other retail loans & & & & & \\
\hline & & & Sovereign & & & & & \\
\hline & & & Other & & & & & \\
\hline & & Foreign loans (to & & & & & & \\
\hline & FVOCI & Bonds & $\begin{array}{l}\text { Sovereign } \\
\text { Nonfinancial corporate }\end{array}$ & & & & & \\
\hline & & (domestic) & Financial corporate & & & & & \\
\hline & & Bonds & Sovereign & & & & & \\
\hline & & (foreign) & $\begin{array}{l}\text { Nontinancial corporate } \\
\text { Financial corporate }\end{array}$ & & & & & \\
\hline & & Equity & Domestic & & & & & \\
\hline & & Other curity & Foreign & & & & & \\
\hline & & (n) & Nonfinancial corporate & & & & & \\
\hline & & & of which SME & & & & & \\
\hline & & Loans (domestic) & Financial corporate & & & & & \\
\hline & & Loans (domestic) & $\begin{array}{l}\text { Household mortgages } \\
\text { Consumer credit and other retail loans }\end{array}$ & & & & & \\
\hline & & & Sovereign & & & & & \\
\hline & & & Other & & & & & \\
\hline & $\begin{array}{c}\text { Amortciza } \\
\text { cost }\end{array}$ & Foreign loans (to & & & & & & \\
\hline & & Bonds & $\begin{array}{l}\text { Sovereign } \\
\text { Nonfinancial corporate }\end{array}$ & & & & & \\
\hline & & (domestic) & Financial corporate & & & & & \\
\hline & & & Sovereign & & & & & \\
\hline & & (foreign) & Nonfinancial corporate & & & & & \\
\hline & & Other & Financial corporate & & & & & \\
\hline Stage ? & & & Nonfinancial corporate & & & & & \\
\hline Stage 2 & & & of which SME & & & & & \\
\hline & & Loans & Financial corporate & & & & & \\
\hline & & (consolidated) & Household mortgages & & & & & \\
\hline & & & Sovereign & & & & & \\
\hline & & & Other & & & & & \\
\hline & & Foreign loans (to & & & & & & \\
\hline & $\mathrm{FVOCI}$ & Bonds & Sovereign & & & & & \\
\hline & & (domestic) & $\begin{array}{l}\text { Nonfinancial corporate } \\
\text { Financial corporate }\end{array}$ & & & & & \\
\hline & & & $\begin{array}{l}\text { Financial corporate } \\
\text { Sovereign }\end{array}$ & & & & & \\
\hline & & $\begin{array}{l}\text { Bonds } \\
\text { (foreign) }\end{array}$ & Nonfinancial corporate & & & & & \\
\hline & & & Financial corporate & & & & & \\
\hline & & Equity & Domestic & & & & & \\
\hline & & Other & Foreign & & & & & \\
\hline & & & Nonfinancial corporate & & & & & \\
\hline & & & of which SME & & & & & \\
\hline & & Loans (domstic & $\begin{array}{l}\text { Financial corporate } \\
\text { Household mortgages }\end{array}$ & & & & & \\
\hline & & Loans (domestic) & $\begin{array}{l}\text { Household mortgages } \\
\text { Consumer credit and other retail loans }\end{array}$ & & & & & \\
\hline & & & Sovereign & & & & & \\
\hline & & & Other & & & & & \\
\hline & $\begin{array}{c}\text { Amorttized } \\
\text { cost }\end{array}$ & Foreign loans (to & & & & & & \\
\hline & & Bonds & Sovereign & & & & & \\
\hline & & (domestic) & \begin{tabular}{|l} 
Nonfinancial corporate \\
Financial corporate
\end{tabular} & & & & & \\
\hline & & & $\begin{array}{l}\text { Fnanclal corporate } \\
\text { Sovereign }\end{array}$ & & & & & \\
\hline & & (foreign) & Nonfinancial corporate & & & & & \\
\hline & & Other & Financial corporate & & & & & \\
\hline Stage 3 & & & Nonfinancial corporate & & & & & \\
\hline & & & of which SME & & & & & \\
\hline & & Loans & Financial corporate & & & & & \\
\hline & & (consolidated) & $\begin{array}{l}\text { Household mortgages } \\
\text { Consumer credit and other retail loans }\end{array}$ & & & & & \\
\hline & & & $\begin{array}{l}\text { Consumere credit and other retall loans } \\
\text { Sovereign }\end{array}$ & & & & & \\
\hline & & & Other & & & & & \\
\hline & & Foreign loans (to & & & & & & \\
\hline & FVOCI & & Sovereign & & & & & \\
\hline & & $\begin{array}{l}\text { Bonds } \\
\text { (domestic) }\end{array}$ & Nonfinancial corporate & & & & & \\
\hline & & & Financial corporate & & & & & \\
\hline & & Bonds & $\begin{array}{l}\text { Sovereign } \\
\text { Nonfinancial corporate }\end{array}$ & & & & & \\
\hline & & (foreign) & Financial corporate & & & & & \\
\hline & & Equity & Domestic & & & & & \\
\hline & & & Foreign & & & & & \\
\hline & & Other & & & & & & \\
\hline & & Bonds & Sovereign bonds & & & & & \\
\hline & & (domestic) & $\begin{array}{l}\text { Nonfinancial corporate bonds } \\
\text { Financial corporate bonds }\end{array}$ & & & & & \\
\hline & & & Sovereign bonds & & & & & \\
\hline & VPt & $\begin{array}{l}\text { Bonds } \\
\text { (foreign) }\end{array}$ & Nonfinancial corporate bonds & & & & & \\
\hline & VPL & & Financial corporate bonds & & & & & \\
\hline & & Equity & Domestic & & & & & \\
\hline & & Derivatives & Forelgn & & & & & \\
\hline & & other & & & & & & \\
\hline
\end{tabular}

Notes: BS abbreviates 'balance sheet'. 


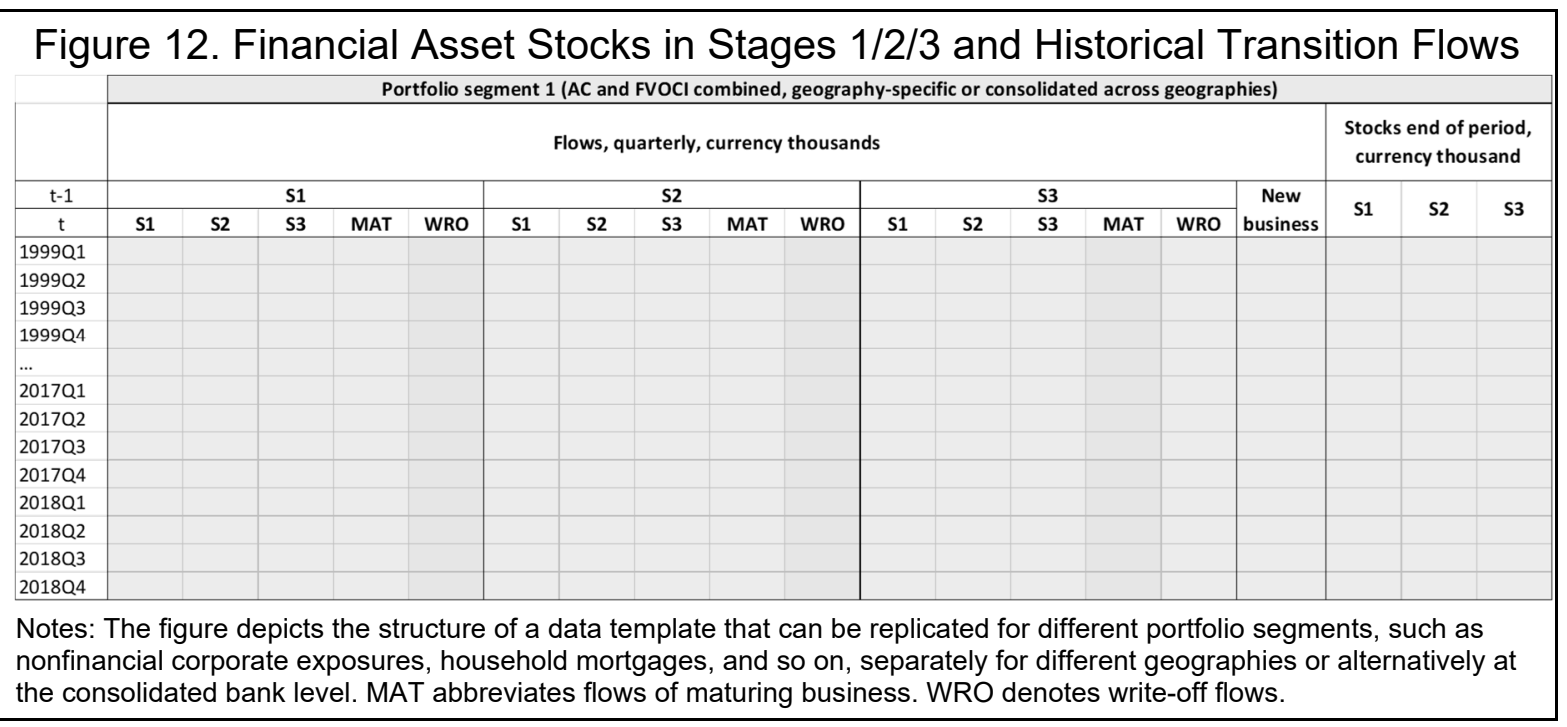

\section{Conclusions}

The first aim of this paper was to present an overview of what ECL implies from a macro-financial system and economics perspective. The "economics of ECL" discussion referred and drew parallels to the literature, both academic and policy-oriented, about heterogeneity in provisioning models, assumptions and limited comparability across banks, procyclicality of accounting regimes, and the lack of incentives for banks to measure risk appropriately in competitive market economies.

The second aim of the paper was to present an integrated tool suite that may form the starting point for analytical, top-down IFRS 9- and CECL-compatible solvency

analyses. This tool suite can be employed for solvency stress test purposes for banks and is meant to serve as an example for top-down macro and macroprudential stress test-oriented institutions, including supervisory bodies, central banks, and other international organizations. The aim was to bring a series of relevant formulae and model elements related to transition matrix modeling, lifetime PD modeling, two variants of a structural LGD model for real estate collateralized portfolios, and a link to risk-weighted assets and capital calculations.

IMF FSAPs in 2019 and 2020 applied the several model options presented in this paper. The Canada 2019 FSAP stress test results show that in the adverse scenario, and when compared to the baseline, credit impairments increase significantly under IFRS 9.

Accounting impairment charges in the adverse scenario would exceed regulatory provisions for most banks, which further underpins the importance of considering the accounting layer in the stress testing exercise. The France 2019 FSAP found that data availability is scarce and may lead to a wide range of estimated losses. Uncertainty is driven by assumptions about loan portfolio growth and differences in loan write-off policies in a sample of banks. For the 2019/20 Korea FSAP (IMF 2020b), long historical transition matrix data were available at the individual bank-portfolio level; they were derived from the stocks and flows of exposures 
under the regulatory risk classification which was mapped into the IFRS 9 accounting stages. This implied that a robust model approach involving elements of the Z-factor methodology could be employed the first time.

It is important for oversight institutions to retain their own, independent models, both in terms of stress test modeling in general and for ECL modeling specifically. An

independent assessment regarding scenario design and stress testing is warranted due to the inherent incentives for financial institutions to underestimate risk, which banks may be able to exploit due to the principles-based nature of the accounting framework. The differences between institutional and bank-internal stress testing approaches could be significant. Understanding the drivers of such differences can be a challenging task, given the complexity of the model suites, the difference in the aggregation level and perimeter, and the discrepancies in prevailing assumptions underpinning either type of stress tests. A significant body of literature confirms such distorted incentives on the side of banks, which we have referenced in the paper. 


\section{REFERENCES}

Abad, J., and J. Suarez, 2017. “Assessing the Cyclical Implications of IFRS 9: A Recursive Model,” European Systemic Risk Board Occasional Paper No. 12.

Allen, F., and E. Carletti, 2008. "Mark-to-Market Accounting and Liquidity Pricing," Journal of Accounting and Economics, 45(2-3), 358-78.

Almeida, H., M. Campello, and C. Liu, 2006. "The Financial Accelerator: Evidence from International Housing Markets," Review of Finance, 10(3), 321-52.

ABA, 2018. "Loss Rate Calculations and the Use of Historical Experience under CECL," American Bankers Association Discussion Paper.

Angeloni, I., and E. Faia, 2013. "Capital Regulation and Monetary Policy with Fragile Banks," Journal of Monetary Economics, 60(3), 311-24.

Asea, P.K., and B. Blomberg, 1998. "Lending Cycles," Journal of Econometrics, 83(1), 89128.

Bangia, A., F.X. Diebold, A. Kronimus, and others, 2002. "Ratings Migration and the Business Cycle, with Application to Credit Portfolio Stress Testing," Journal of Banking \& Finance, 26, 445-74.

BCBS, 2005. "Validation of Low-Default Portfolios in the Basel II Framework," Basel Committee Newsletter No. 6, September 2005.

, 2015. "Guidance on Credit Risk and Accounting for Expected Credit Losses," Basel Committee on Banking Supervision, December 2015.

Banking Supervision Discussion Paper, October 2016.

—, 2017. "Standards: Regulatory Treatment of Accounting Provisions-Interim Approach and Transitional Arrangements," Basel Committee on Banking Supervision, Standards.

Beatty, A., S. Chamberlain, and J. Magliolo, 1996. "An Empirical Analysis of the Economic Implications of Fair Value Accounting for Investment Securities," Journal of Accounting and Economics, 22(1-3), 43-77.

Becker, G.S., 1991. "A Note on Restaurant Pricing and Other Examples of Social Influences on Price," Journal of Political Economy, 99(5), 1109-16.

Begley, T.A., A. Purnanandam, and K. Zheng, 2017. "The Strategic Underreporting of Bank

Risk," Review of Financial Studies, 30(10), 3376-415.

Behn, M., R. Haselmann, and V. Vig, 2016. "The Limits of Model-Based Regulation," European Central Bank Working Paper No. 1928.

Belkin, B., S. Suchower, and L.R. Forest, 1998. "A One-Parameter Representation of Credit Risk and Transition Matrices," CreditMetrics Monitor, Third Quarter 1998.

Berger, A.N., and G.F. Udell, 2004. "The Institutional Memory Hypothesis and the Procyclicality of Bank Lending Behavior," Journal of Financial Intermediation, 13(4), 45895. 
Bernanke, B.S., M. Gertler, and S. Gilchrist, 1999. "The Financial Accelerator in a Quantitative Business Cycle Framework," in Handbook of Macroeconomics, Vol. 1, 134193. Amsterdam, Netherlands: Elsevier Academic Press.

Blum, J., and M. Hellwig, 1995. "The Macroeconomic Implications of Capital Adequacy Requirements for Banks," European Economic Review, 39(3), 739-49. Papers and Proceedings of the Ninth Annual Congress European Economic Association.

BoE, 2017. "Clarification on IFRS 9 for 2018 ICAAP Stress Testing and Capital Planning," Bank of England, October 25, 2017.

—, 2018. Bank of England Financial Stability Report, Issue No. 44.

_ 2019. "Stress Testing the UK Banking System: 2019 Guidance for Participating Banks and Building Societies," Bank of England, March 2019.

Boyd, J.H., and G.D. Nicolo, 2005. "The Theory of Bank Risk Taking and Competition Revisited," Journal of Finance, 60(3), 1329-43.

Brunnermeier, M.K., and Y. Sannikov, 2014. "A Macroeconomic Model with a Financial Sector," American Economic Review, 104(2), 379-421.

Buesa, A., F.J. Población García, and J. Tarancón, 2019. "Measuring the Procyclicality of Impairment Accounting Regimes: A Comparison between IFRS 9 and US GAAP," European Central Bank Working Paper No. 2347.

Bushman, R.M., and C.D. Williams, 2015. "Delayed Expected Loss Recognition and the Risk Profile of Banks," Journal of Accounting Research, 53, 511-53.

Chae, S., R.F. Sarama, C.M. Vojtech, and others, 2018. "The Impact of the Current Expected Credit Loss Standard (CECL) on the Timing and Comparability of Reserves," Finance and Economics Discussion Series 2018-020, Board of Governors of the Federal Reserve System (US).

Danielsson, J., H.S. Shin, and J.-P. Zigrand, 2012. "Procyclical Leverage and Endogenous Risk," unpublished. London School of Economics and Political Science, http://www.riskresearch.org.

, M. Valenzuela, and I. Zer, 2016. "Learning from History: Volatility and Financial Crises," LSE Research Online Documents on Economics 66046, London School of Economics and Political Science, LSE Library.

Day, R.H., and W. Huang, 1990. "Bulls, Bears and Market Sheep," Journal of Economic Behavior \& Organization, 14(3), 299-329.

Deloitte, 2018. “The Post-IFRS 9 Era for Lending Industry,” Sofia, June 4, 2018.

EBA, 2016. "Report on Results from the EBA Impact Assessment of IFRS 9," European Banking Authority, December 2016.

—, 2017. "EBA Report on Results from the Second EBA Impact Assessment of IFRS 9,” European Banking Authority, July 13, 2017.

—, 2018a. “2018 EU-Wide Stress Test-Methodological Note,” European Banking Authority, January 31, 2018. 
—_, 2018b. "2018 EU-Wide Stress Test—Results," European Banking Authority, November 2, 2018.

EC, 2016. “Commission Regulation (EU) 2016/2067 amending Regulation (EC) No. 1126/2008 adopting certain international accounting standards in accordance with Regulation (EC) No. 1606/20002 of the European Parliament and of the Council as regards International Financial Reporting Standard 9," Official Journal of the European Union.

ECB, 2020. "ECB Banking Supervision Provides Further Flexibility to Banks in Reaction to Coronavirus," European Central Bank Press Release, March 20, 2020, https://www.bankingsupervision.europa.eu/press/pr/date/2020/html/ssm.pr200320 4cdbbcf4 66.en.html.

ESRB, 2017. "Financial Stability Implications of IFRS 9," European Systemic Risk Board, July 2017.

EY, 2016. "Regulatory Treatment of Accounting Provisions: An Update on Global and European Developments," Ernst \& Young, March 2018.

- 2018a. "Applying IFRS: Impairment of Financial Instruments under IFRS 9," Ernst \& Young, April 2018. , 2018b. “EY IFRS 9 Impairment Banking Survey,” Ernst \& Young, August 2017.

Estrella, A., 2004. “The Cyclical Behavior of Optimal Bank Capital,” Journal of Banking \& Finance, 28(6), 1469-98.

FASB, 2016. "Financial Instruments—Credit Losses (Topic 326): Measurement of Credit Losses on Financial Instruments," Financial Accounting Standards Board.

Firestone, S., and M. Rezende, 2016. "Are Banks' Internal Risk Parameters Consistent? Evidence from Syndicated Loans," Journal of Financial Services Research, 50, 211-42.

FSB, 2009. "Recommendations for Addressing Procyclicality in the Financial System," Financial Stability Board, April 2, 2009.

FSF, 2008, “Addressing Financial System Procyclicality: A Possible Framework," note for the Financial Stability Forum Working Group on Market and Institutional Resilience.

Gaston, E., and I.W. Song, 2014. "Supervisory Roles in Loan Loss Provisioning in Countries Implementing IFRS," IMF Working Paper No. 14/170.

Gavalas, D., and T. Syriopoulos, 2014. "Bank Credit Risk Management and Rating Migration Analysis on the Business Cycle," International Journal of Financial Studies, 2, $122-43$.

Gordy, M.B., 2003. “A Risk-Factor Model Foundation for Ratings-Based Bank Capital Rules," Journal of Financial Intermediation, 12,199-232.

Gross, M., Hilberg, B., van der Hoog, S., and D. Kohlweyer, 2020. “The Eurace@IMF+ECB Model", forthcoming.

Gross, M., and J. Población, 2019. "Implications of Model Uncertainty for Bank Stress Testing," Journal of Financial Services Research, 55(1), 31-58. 
Haldane, A., 2013. "Constraining Discretion in Bank Regulation,” Bank of England, speech on April 9, 2013, https://www.bis.org/review/r130606e.pdf.

Huizinga, H., and L. Laeven, 2019. "The Procyclicality of Banking: Evidence from the Euro Area," Centre for Economic Policy Research Discussion Paper 13605.

IASB, 2014. "IFRS 9 Financial Instruments," International Accounting Standards Board, July 2014.

IMF, 2019a. "France FSAP: Risk Analysis of Banking and Insurance Sector," Technical Note, https://www.imf.org/en/Publications/CR/Issues/2019/10/28/France-Financial-SectorAssessment-Program-Technical-Note-Risk-Analysis-of-Banking-and-48758.

_ 2019b. "Singapore FSAP: Financial Stability Analysis and Stress Testing," Technical Note, https://www.imf.org/en/Publications/CR/Issues/2019/07/15/SingaporeFinancial-Sector-Assessment-Program-Technical-Note-Financial-Stability-Analysis-47112. , 2020a. "Canada FSAP: Stress Testing and Financial Stability Analysis," Technical Note, https:/www.imf.org/en/Publications/CR/Issues/2020/01/23/Canada-Financial-SectorAssessment-Program-Technical-Note-Stress-Testing-and-Financial-48970.

_ 2020b. "Korea FSAP: Systemic Risk Analysis and Financial Sector Stress Testing," Technical Note, forthcoming.

_ 2020c. "Latvia FSAP: Financial Stability Analysis and Stress Testing," Technical Note, forthcoming.

Jafry, Y., and T. Schuermann, 2004. "Measurement, Estimation and Comparison of Credit Migration Matrices,” Journal of Banking \& Finance, 28(11), 2603-39.

Jimenez, G., and J. Saurina, 2006. "Credit Cycles, Credit Risk, and Prudential Regulation," International Journal of Central Banking, 2(2), 65-98.

Kashyap, A.K., and J.C. Stein, 2004. "Cyclical Implications of the Basel II Capital Standards," Economic Perspectives, 18-31.

Kirman, A., 1993. “Ants, Rationality, and Recruitment,” Quarterly Journal of Economics, 108(1), 137-56.

Kiyotaki, N., and Moore, J., 1997. "Credit Cycles,” Journal of Political Economy, 105(2), 211-48.

Lando, D., and T.M. Skodeberg, 2002. "Analyzing Rating Transitions and Rating Drift with Continuous Observations," Journal of Banking \& Finance, 26(2-3), 423-44.

Laux, C., and C. Leuz, 2010, "Did Fair-Value Accounting Contribute to the Financial Crisis?" Journal of Economic Perspectives, 24(1), 93-118.

Maehlmann, T., 2006. "Estimation of Rating Class Transition Probabilities with Incomplete Data," Journal of Banking \& Finance, 30(11), 3235-526.

Malik, M., and L.C. Thomas, 2012. "Transition Matrix Models of Consumer Credit Ratings," International Journal of Forecasting, 28(1), 261-72.

Mariathasan, M., and O. Merrouche, 2014. "The Manipulation of Basel Risk-Weights," Journal of Financial Intermediation, 23(3), 300-21. 
Martinez-Miera, D., and R. Repullo, 2010. "Does Competition Reduce the Risk of Bank Failure?" Review of Financial Studies, 23(10), 3638-64.

Moody's Analytics, 2017. "Credit Transition Model 2017 Update: Methodology and Performance Review," by Wang, Y, Ding, M., Pan, J. J. and Malone, S. October.

Mullainathan, S., 2002. "A Memory-Based Model of Bounded Rationality," The Quarterly Journal of Economics, 117(3), 735-74.

Nickell, P., W. Perraudin, and S. Varotto, 2000. "Stability of Rating Transitions," Journal of Banking \& Finance, 24, 203-27.

Novotny-Farkas, Z., 2015. "The Significance of IFRS 9 for Financial Stability and Supervisory Rules," study for the ECON Committee of the European Parliament.

Papke, E., and J.M. Wooldridge, 1996. "Econometric Methods for Fractional Response Variables with an Application to 401(K) Plan Participation Rates," Journal of Applied Econometrics, 11(6), 619-32.

Plosser, M., and J. Santos, 2014. "Banks' Incentives and the Quality of Internal Risk Models," Federal Reserve Bank of New York Staff Report 704.

PWC, 2017. "IFRS 9, Financial Instruments_-Understanding the Basics," PricewaterhouseCoopers.

, 2018. "In Depth_A Look at Current Financial Reporting Issues_-IFRS9: What's New in Financial Instruments Accounting for Asset Management," PricewaterhouseCoopers, February.

Repullo, R., 2004. "Capital Requirements, Market Power, and Risk-Taking in Banking," Journal of Financial Intermediation, 13(2), 156-82.

Ruckes, M., 2004. "Bank Competition and Credit Standards," The Review of Financial Studies, 17(4), 1073-102.

Scharfstein, D.S., and J.C. Stein, 1990. "Herd Behavior and Investment," The American Economic Review, 80(3), 465-79.

SSM, 2019. "SSM-Wide Stress Test 2018_Final Results," European Central Bank (ECB)/Single Supervisory Mechanism (SSM), presentation slides (https://www.bankingsupervision.europa.eu/press/pr/date/2019/html/ssm.pr190201 presentat ion.en.pdf), February 1, 2019.

-, 2020. "IFRS 9 in the Context of the Coronavirus (Covid-19) Pandemic," letter to all significant institutions under SSM supervision, April 1, 2020, https://www.bankingsupervision.europa.eu/press/letterstobanks/shared/pdf/2020/ssm.2020 le tter IFRS 9 in the context of the coronavirus COVID-19 pandemic.en.pdf.

Truck, S., 2008. "Forecasting Credit Migration Matrices with Business Cycle Effects: A Model Comparison," European Journal of Finance, 14, 359-79.

—, and T. Rachev, 2009. "Rating Based Modelling of Credit Risk: Theory and Application of Migration Matrices," Amsterdam, Netherlands: Elsevier Academic Press.

Wei, J.Z., 2003. "A Multi-Factor, Credit Migration Model for Sovereign and Corporate Debts," Journal of International Money and Finance, 22(5), 709-35. 
Truck, S. (2008), "Forecasting credit migration matrices with business cycle effects: A model comparison," European Journal of Finance, 14:359-379.

Truck, S. and Rachev, T. (2009), "Rating based modelling of credit risk: Theory and application of migration matrices," Elsevier Academic Press: Amsterdam, Netherlands, 2009.

Wei, J. Z. (2003), "A multi-factor, credit migration model for sovereign and corporate debts," Journal of International Money and Finance, 22(5):709-735. 